\title{
Opportunities, Barriers and Actions for Industrial Demand Response in California
}

\author{
Aimee T. McKane, Mary Ann Piette, David Faulkner, Girish Ghatikar, Anthony \\ Radspieler Jr., Bunmi Adesola, Scott Murtishaw and Sila Kiliccote \\ Lawrence Berkeley National Laboratory \\ 1 Cyclotron Road \\ Berkeley, California 94720
}

January 2008

The work described in this report was coordinated by the Demand Response Research Center and funded by the California Energy Commission, Public Interest Energy Research Program under Work for Others Contract No. 500-03-026 and by the U.S. Department of Energy under Contract No. DE-AC0205CH11231. 


\section{Acknowledgements}

The authors are grateful for the extensive support from numerous individuals who assisted in this project. Special thanks to Mike Gravely and Kristy Chew from the California Energy Commission and Greg Wickler of Global Energy Partners. This work described in this report was coordinated by the Demand Response Research Center and funded by the California Energy Commission, Public Interest Energy Research Program, under Work for Others Contract No.500-03-026 and by the U.S. Department of Energy under Contract No. DE-AC02-05CH11231.

\section{Disclaimer}

This document was prepared as an account of work sponsored by the United States Government. While this document is believed to contain correct information, neither the United States Government nor any agency thereof, nor The Regents of the University of California, nor any of their employees, makes any warranty, express or implied, or assumes any legal responsibility for the accuracy, completeness, or usefulness of any information, apparatus, product, or process disclosed, or represents that its use would not infringe privately owned rights. Reference herein to any specific commercial product, process, or service by its trade name, trademark, manufacturer, or otherwise, does not necessarily constitute or imply its endorsement, recommendation, or favoring by the United States Government or any agency thereof, or The Regents of the University of California. The views and opinions of authors expressed herein do not necessarily state or reflect those of the United States Government or any agency thereof or The Regents of the University of California. 


\section{Preface}

The Public Interest Energy Research (PIER) Program supports public interest energy research and development that will help improve the quality of life in California by bringing environmentally safe, affordable, and reliable energy services and products to the marketplace.

The PIER Program, managed by the California Energy Commission (Energy Commission), conducts public interest research, development, and demonstration (RD\&D) projects to benefit California.

The PIER Program strives to conduct the most promising public interest energy research by partnering with RD\&D entities, including individuals, businesses, utilities, and public or private research institutions.

PIER funding efforts are focused on the following RD\&D program areas:

- $\quad$ Buildings End - Use Energy Efficiency

- $\quad$ Energy Innovations Small Grants

- $\quad$ Energy - Related Environmental Research

- $\quad$ Energy Systems Integration

- $\quad$ Environmentally Preferred Advanced Generation

- Industrial/Agricultural/Water End - Use Energy Efficiency

- $\quad$ Renewable Energy Technologies

- Transportation

Opportunities, Barriers, and Actions for Industrial Automated Demand Response in California is the year-end report for the Industrial Demand Response Strategic Roadmap Project (Contract No.500-03-026, Task 5.4) conducted by Lawrence Berkeley National Laboratory. The information from this project contributes to PIER's Industrial/Agricultural/Water End-Use Energy Efficiency Program.

For more information about the PIER Program, please visit the Energy Commission's website at www.energy.ca.gov/pier or contact the Energy Commission at 916-654-5164 


\section{Table of Contents}

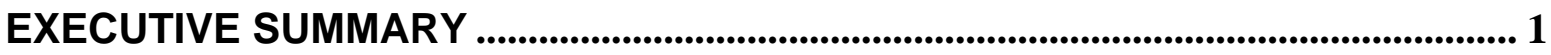

1.0 INTRODUCTION .................................................................................................... 6

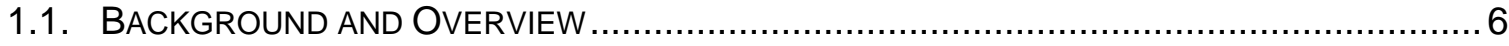

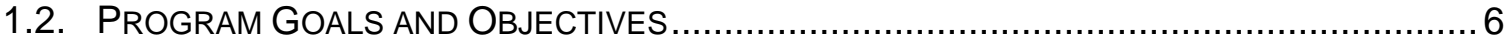

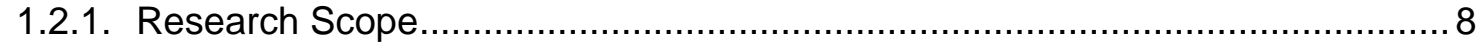

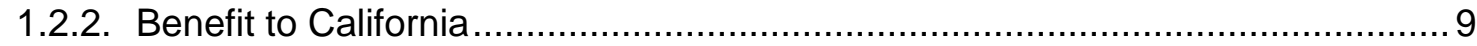

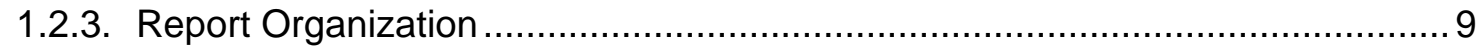

1.2.4. Previous Research.......................................................................... 10

1.2.4.1. Industrial Demand Response ........................................................ 10

1.2.4.2. Industrial Energy Usage Patterns ................................................... 11

1.3. TERMS AND CONCEPTS FOR INDUSTRIAL AUTO DR STRATEGIES .......................... 16

2.0 PROGRAM ACTIVITIES ............................................................................... 19

2.1. InduStRIAL DEMAND RESPONSE StRATEgIC RESEARCH ROADMAP ........................ 19

2.2. UTILITY INDUSTRIAL INTEGRATED AUDIT DEMAND RESPONSE DATABASE .................. 19

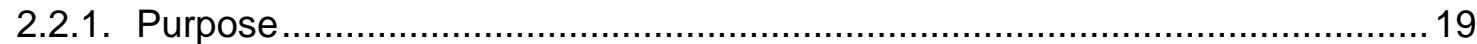

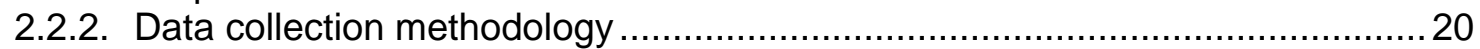

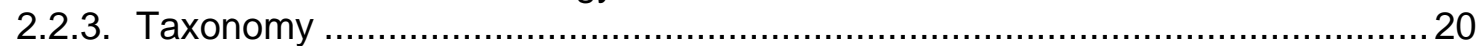

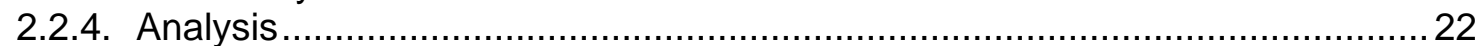

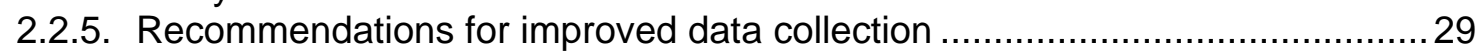

2.3. IDENTIFICATION AND ANALYSIS OF BARRIERS TO IMPLEMENTATION OF INDUSTRIAL

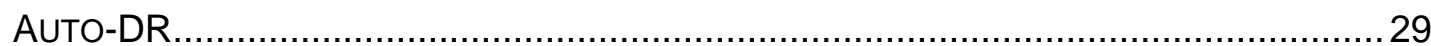

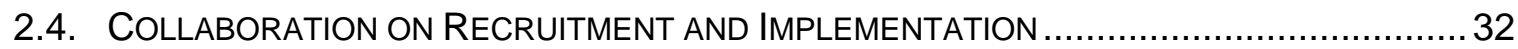

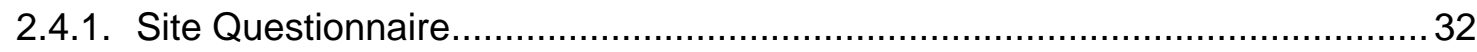

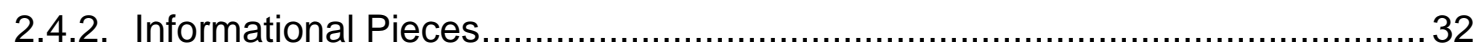

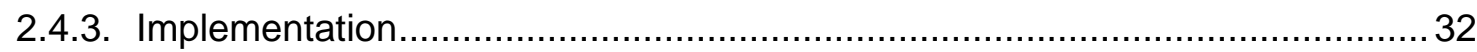

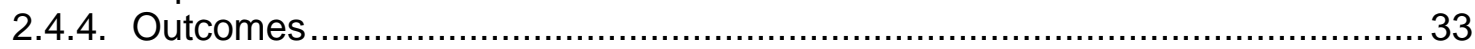

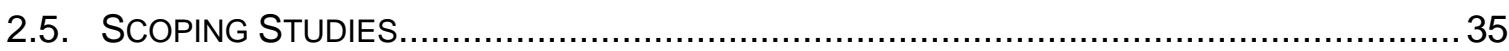

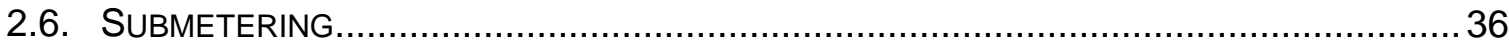

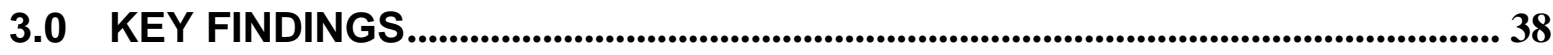

4.0 PROMISING AREAS FOR FUTURE RESEARCH............................................ 42

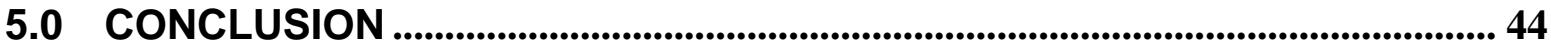

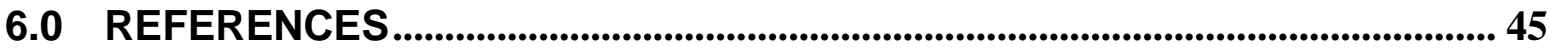

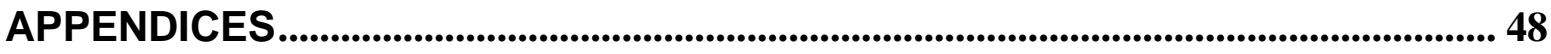

APPENDIX A: INDUSTRIAL DEMAND RESPONSE StRATEGIC RoADMAP ............................. 50

APPENDIX B: INDUSTRIAL DEMAND RESPONSE AUDIT DATABASE STRUCTURE ...................60

APPENDIX C: INDUSTRIAL DEMAND RESPONSE AUDIT DATABASE ANALYSES ......................62

APPENDIX D: QUESTIONS TO ADD TO INTEGRATED ENERGY AUDIT TEMPLATE FOR

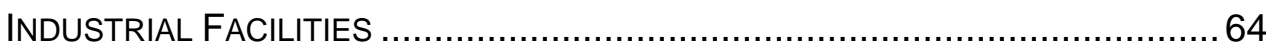

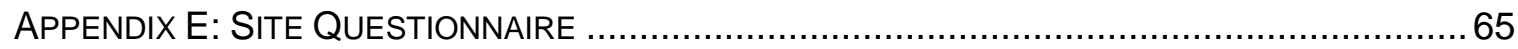

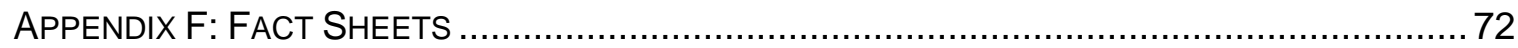

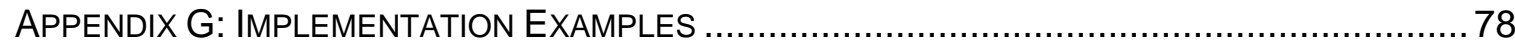




\section{List of Tables}

Table 1. Electricity Used by California Manufacturing Industries, 2004

Table 2. Demand Side Management Framework for Industrial Facilities

Table 3. Industrial Demand Response Potential by Plant Type (Top 25 by Average kW) .. 23

Table 4. Industrial Demand Response Potential by 4-Digit NAICS (Top 25 by Average kW)

Table 5. Comparison by 4-Digit NAICS Category of Top Electricity Consuming

Manufacturing Industries and Industrial Demand Response Potential from Audit

Database Top 25 Industries by Average kW.

Table 6. Industrial Demand Response Potential by Shift/Shed Strategy for Production...... 26

Table 7. Industrial Demand Response Potential by Shift/Shed Strategy for Supporting Systems

Table 8. Industrial Demand Response Potential by Technology/Measure ......................... 28

Table 9. Barriers Analysis of Industrial Demand Response ........................................... 30

Table 10. 2007 PG\&E Auto-DR Participation Profile (industry as a \% the total)............... 34

Table 11. Auto-DR Program Goals and Results ........................................................ 35

Table 12. Industrial Participants in Sub-Metering Study .................................................. 37

\section{List of Figures}

Figure 1. Discovery Process for Industrial Auto-DR Implementation 5

Figure 2. Demand Profile of Various Demand Response Methods in Industrial Facilities.. 17

Figure 3. Generic Automated DR Open-Interface Standard Architecture ......................... 18

Figure 4. Industrial Demand Response Audit Database Taxonomy .................................. 21

Figure 5. Load Shed Test August 30, 2007................................................................. 33 


\section{Executive Summary}

\section{Overview}

In 2006 the Demand Response Research Center (DRRC) formed an Industrial Demand Response Team to investigate opportunities and barriers to implementation of Automated Demand Response (Auto-DR) systems in California industries. Auto-DR is an open, interoperable communications and technology platform designed to:

- Provide customers with automated, electronic price and reliability signals;

- Provide customers with capability to automate customized DR strategies;

- Automate DR, providing utilities with dispatchable operational capability similar to conventional generation resources.

This research began with a review of previous Auto-DR research on the commercial sector. Implementing Auto-DR in industry presents a number of challenges, both practical and perceived. Some of these include: the variation in loads and processes across and within sectors, resource-dependent loading patterns that are driven by outside factors such as customer orders or time-critical processing (e.g. tomato canning), the perceived lack of control inherent in the term “Auto-DR", and aversion to risk, especially unscheduled downtime. While industry has demonstrated a willingness to temporarily provide large sheds and shifts to maintain grid reliability and be a good corporate citizen, the drivers for widespread Auto-DR will likely differ. Ultimately, most industrial facilities will balance the real and perceived risks associated with Auto-DR against the potential for economic gain through favorable pricing or incentives. Auto$\mathrm{DR}$, as with any ongoing industrial activity, will need to function effectively within market structures.

\section{Research Goals}

The goal of the industrial research is to facilitate deployment of industrial Auto-DR that is economically attractive and technologically feasible. Automation will make DR:

- More visible by providing greater transparency through two-way end-to-end communication of DR signals from end-use customers;

- More repeatable, reliable, and persistent because the automated controls strategies that are "hardened" and pre-programmed into facility’s software and hardware;

- More affordable because automation can help reduce labor costs associated with manual DR strategies initiated by facility staff and can be used for long-term

\section{Key Research Questions}

To help frame this research, we formulated five research questions. While much can be learned from the current empirical approach of "learn by doing", the limited findings from the first year led to questions concerning assumptions about industrial Auto-DR. Although this market is complex, substantial research opportunities exist to target promising sectors and systems to gain a better understanding of their potential, while also providing a forum to foster and accelerate DR-compatible advances in industrial controls. For its second year of research, the DRRC 
Industrial Team plans to build on our initial findings and focus the research on answers to the following key questions:

1. Where is the potential to shed or shift electricity use in industry?

- Which sectors have the greatest potential to shed or shift during peak periods?

- Have these sectors been active in reliability programs or identified in audits?

2. What is the functional capability of specific industries to implement Auto-DR?

- What are the control gaps and the associated cost of implementing Auto-DR?

- Of sectors identified as having Auto-DR potential, which offer the most cost-effective implementation opportunities?

3. What are the market trends in industrial controls that support Auto-DR?

- Do advances in control technologies make specific sectors or systems attractive candidates for Auto-DR?

- What are the technology gaps that might benefit from public R\&D?

4. What are the market and operational barriers to the implementation of reliability and price-responsive industrial DR?

- Do industrial energy managers understand economic and societal benefits of DR?

- What roles do price and incentives have in the decision making process?

- What are the areas tension between DR and industrial plant schedules?

5. What is the role of industrial Auto-DR in the state's goal to provide reliable and climate-friendly electricity at a reasonable cost to CA consumers?

- Is there "migration potential” for DR strategies in promoting industrial load management and energy efficiency in industrial facilities?

Developing a greater understanding of the opportunity for Auto-DR is timely because the market for better controls and facility wide enterprise energy management is immature, but emerging rapidly. Early entries into this market have focused on load management, but these tools and strategies, if DR enabled, hold significant promise for integration into an Auto-DR framework. Similarly, the emergence of higher quality system level network controls provide the missing link to allow improved management of key energy systems, and thus greater opportunities for DR and overall energy efficiency. The complete integration of load management, DR, and energy efficiency across an entire industrial plant may be within reach of many plants within the next decade. Under this scenario, even plants without onsite generation could, under predetermined conditions, free up electricity to the grid to preserve the system reliability and manage the cost of delivering statewide electricity while maintaining the economic health of their businesses.

The DRRC has outlined a research methodology for implementation of Auto-DR. The potential Auto-DR seems substantial and attainable. Within the next two or three years specific sectors 
will be targeted with a menu of potential Auto-DR strategies, enabled by the rapid growth of improved industrial controls to support these strategies.

\section{Key Findings in 2007}

There appears to be great potential for Auto-DR in industrial facilities. This finding needs to be qualified with further research to understand 1) organizational decision-making processes as they impact DR participation and 2) the role of existing and emerging industrial controls in facilitating participation in Auto-DR, 3) end-use process controls to support reduced service and process control levels during DR events.

Key Finding: Some industrial facilities will shift or shed process load based on financial incentives, not just to protect reliability.

- In certain niche markets, such as industrial gases, electricity is a large proportion of operating costs. As a result, demand management is an integral part of the operating culture with sophisticated controls. For these markets, Auto-DR offers a costmanagement opportunity that is integrated into the production schedule

- $\quad$ Shifting a batch process, such as a hammer mill, may be acceptable as an Auto-DR strategy even if it is not be something done on a daily basis.

Key Finding: Auto-DR is compatible with energy efficiency and load management in industrial facilities

- $\quad$ Plants who express interest in Auto-DR are typically already engaged in both energy efficiency and demand management improvements. Auto-DR is another cost-reduction tool, not a replacement for efficiency and demand management.

Key Finding: Many industries have limited controls, especially for supporting or non-core systems that may be suited for Auto-DR. There is an emerging market for demand management and system-level network controls that could allow Auto-DR to be integrated. Discrete controls offer less Auto-DR capability.

Our research identified opportunities for demonstrations or case studies in several areas:

- Adaptation of existing demand management software for Auto-DR applications;

- Minor modification to make network controls for supporting systems DR-enabled;

- Modification of Auto-DR software designed for energy efficiency and load management in data centers;

- Opportunities to "think beyond the plant" by bundling similar Auto-DR shed strategies into a single controls network so that sheds could be "tuned" to actual needs within the scope of individual participation agreements.

Key Finding: The current portfolio of DR programs is confusing, but the availability of financial incentives and technical assistance can make participation attractive. 
Industrial facilities are not concerned with DR, since their focus is on core production. The current DR programs and tariffs are so complex that they create challenges. Unless the incentives are substantial, most industries are not willing to study the potential benefits. A simpler approach is needed.

Key Finding: It is possible to define DR shed/shift strategies for specific industries. We can develop preliminary "short lists" for promising sectors to further evaluate their feasibility.

Although the sample size was limited (207 records) and is based on recommended rather than implemented strategies, nine 4-digit NAICS categories were identified as in the top-25 for both large users of manufacturing electricity (Table 1) and DR potential by average $\mathrm{kW}$ from the utility integrated audits (Table 4). These categories include:

- Converted Paper Product manufacturing

- Fruit and Vegetable Preserving and Specialty Food Manufacturing

- Basic chemical manufacturing, especially industrial gases

- Dairy Product manufacturing

- Aerospace Product and Parts Manufacturing

- Other Fabricated Metal Product Manufacturing

- Animal Slaughtering and Processing

- Bakeries and Tortilla Manufacturing

- Beverage Manufacturing

Of these, the industrial gas sector appears ready for implementation. Anecdotal evidence from industrial end users indicates that DR opportunities may be found in other industrial sectors. The key research question is "to what extent can and will these facilities accept automation of DR?" The nine sectors listed above were compared against recommendations in other related reports ${ }^{1}$. We recommend an initial "short list" of five industrial sectors recommended for further study based on knowledge of these sectors:

- Cold storage

- Data centers and test labs for high tech industries

- Water/wastewater

- Aerospace products

- Beverages, including breweries and wineries

While there is a wide range of potential shift and shed strategies requiring further study, those most frequently identified in the utility integrated audits are:

- For production shifts, conveyors, all systems, pump systems, and electrical;

- For production sheds, all systems (stop production), finishing, process cooling and pump systems;

\footnotetext{
${ }^{1}$ These reports are: Evaluation of 2005 Statewide Large Nonresidential Day-Ahead and Reliability Demand Response Programs by Quantum Consulting (2006) and Demand Response Analysis and Tool Development for Industrial, Agricultural and Water (IAW) Energy Users by EPRI for the California Energy Commission (2005).
} 
- For supporting system load shifts, space conditioning, motors, process cooling, and storage; and

- For supporting system load sheds, aerators, multiple systems, electrical, and compressed air.

\section{Future Research}

For the second year of research, the DRRC proposes to work with a Technical Advisory Group comprised of representatives from industry and the suppliers and consultants that work with them. This research will be directed toward key research questions outlined above to assist the California Energy Commission (CEC), the California Public Utilities Commission (CPUC), and the investor-owned utilities in more effectively targeting their Auto-DR efforts. Figure 1 below shows a proposed organizational framework.

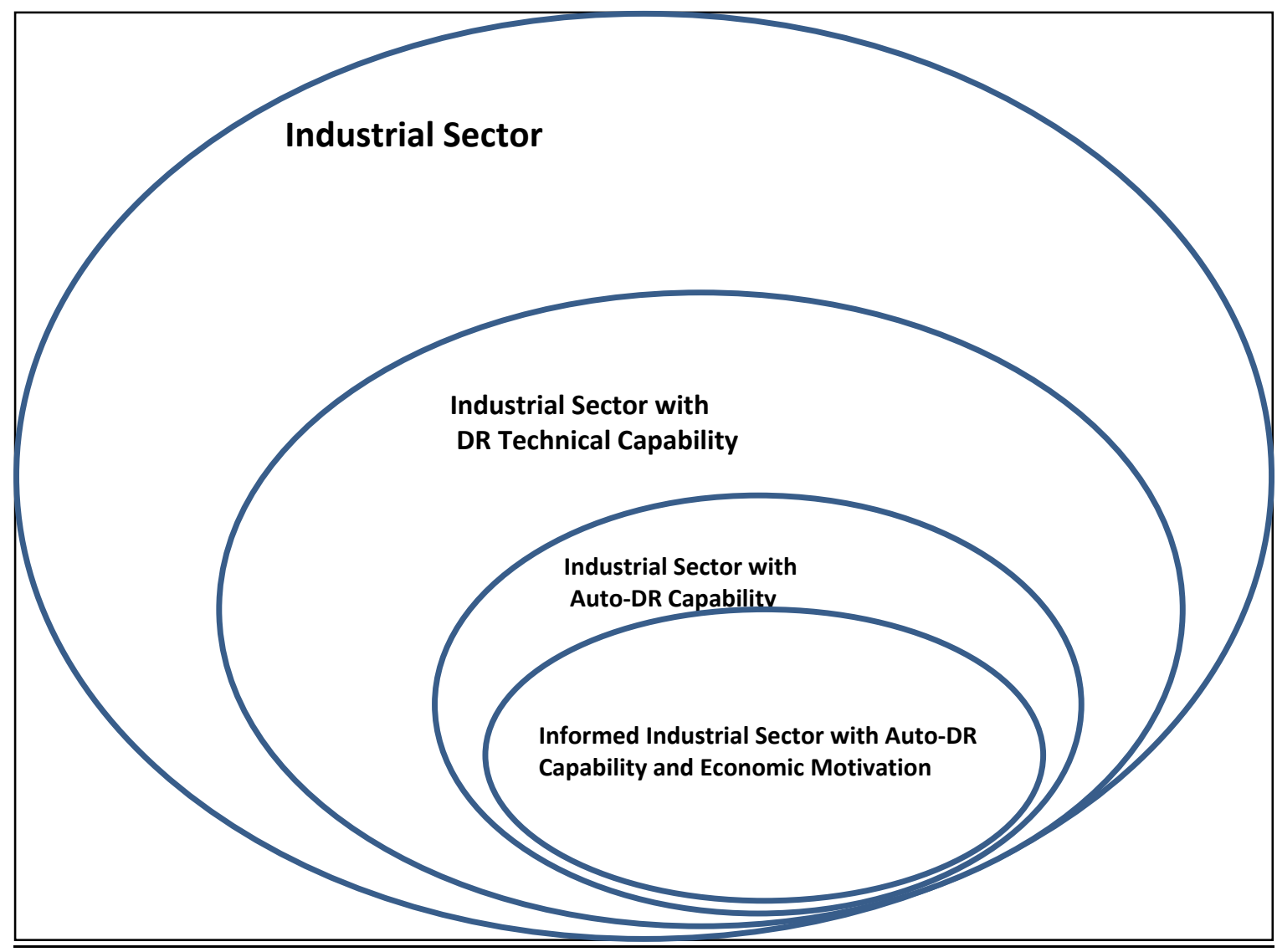

Figure 1. Discovery Process for Industrial Auto-DR Implementation 


\subsection{Introduction}

\subsection{Background and Overview}

Demand Response (DR) is a set of actions taken to reduce electric loads when contingencies, such as emergencies or congestion, occur that threaten supply-demand balance, and/or market conditions occur that raise electric supply costs. DR programs and tariffs are designed to improve the reliability of the electric grid and to lower the use of electricity during peak times to reduce the total system costs. Automated Demand Response (Auto-DR) is a set of standard, continuous, open communication signals and systems provided over the Internet to allow facilities to automate their demand response with no "human in the loop."

The Demand Response Research Center (DRRC) at Lawrence Berkeley National Laboratory (LBNL) has tested Auto-DR systems in over 50 commercial buildings over the last four years. Most of the building strategies have focused on lighting, cooling, and ventilation system strategies automated through building Energy Management Control Systems (EMS). Historically, California (CA) industries have participated in a number of DR programs on a manual basis, including day-ahead and day-of programs such as Demand Bidding Program (DBP), Base Interruptible Program (BIP), Capacity Bidding Program (CBP), and Critical Peak Pricing Program (CPP).

Implementing industrial Auto-DR presents a number of challenges, both practical and perceived. Some of these include: the wide variation in loads and processes across sectors and even within sectors, resource-dependent loading patterns that are driven by outside factors such as customer orders or time-critical processing (e.g. tomato canning), the perceived lack of control inherent in the term “Auto-DR”, and aversion to risk, especially unscheduled downtime. In October 2006, an Industrial Demand Response Team was formed at LBNL under the auspices of the DRRC (identified in this report as the DRRC Industrial Team) to investigate opportunities and barriers to implementation of Auto-DR in California Industries. This report represents the results of the first year of research by the team.

\subsection{Program Goals and Objectives}

The California Energy Commission (CEC) has outlined a reach goal of achieving 448 megawatts (MW) of peak demand reduction (DR) from the industrial sector by $2008^{2}$. The industrial sector represents $20 \%$ of the base electricity peak demand, or approximately $8600 \mathrm{MW}$. In addition to the opportunities in industrial energy efficiency and demand management, preliminary estimates indicate that $30-40 \%$ of industrial loads may be automatic demand response (Auto-DR) candidates $^{3}$. To date, California's Auto-DR activity has been focused largely on the commercial buildings sector. While many industrial facilities have participated in reliability and "day ahead" notification programs (1857 MW and 1044 MW, respectively in 2005 - the latest date for which

\footnotetext{
${ }^{2}$ CPUC D.04-09-060, AB 32 as cited in California Energy Commission’s PIER Industrial Efficiency Strategic Plan, 2007

${ }^{3}$ PIER Demand Response R\&D Strategy, Commissioner Geesman Briefing August 24, 2006
} 
a complete evaluation is available), only a small number of industrial sites have participated in other types of DR. ${ }^{4}$

Developing a greater understanding of the magnitude and practical application of Auto-DR is particularly timely. In the past few years, a number of companies have either initiated, or expressed serious interest in, the development of new product offerings designed to provide plant managers with software and hardware tools to more closely manage their energy use in real time. The market for energy management controls or energy enterprise management is still quite immature, but emerging rapidly. Early entries into this market have focused largely on load management, but these same tools and strategies, if DR enabled, hold significant promise for integration into an Auto-DR framework. Similarly, the emergence of higher quality system level network controls provide the missing link that would allow much tighter management of energy end use, and thus both greater opportunities for demand response as well as higher overall energy efficiency. The complete integration of load management, demand response, and energy efficiency across an entire industrial plant may be within reach of many plants within the next decade. These systems will permit the plant of the future to manage electricity, and potentially natural gas, for price and for actual, rather than perceived, demand. Under this scenario, even plants without any onsite generation capability could, under pre-determined conditions, automatically free up electricity to the grid in order to preserve the reliability and/or manage the cost of delivering electricity statewide while maintaining the economic health of their businesses.

Historically, industrial DR programs have engaged facilities to participate in manual or semiautomated demand response largely in response to reliability issues. In its inaugural year, the DRRC Industrial Team began conducting research on strategies for engaging CA industry in Auto-DR, with a particular focus on the practical potential of 1) small, frequent sheds or shifts that could be accommodated without any significant disruption in facility operations and 2) the decision-making strategies that facilities might apply in evaluating the attractiveness of a priceresponsive (as opposed to reliability) shed or shift. The research seeks to build on lessons from the successful implementation of DR in the commercial sector as well as knowledge acquired by the CEC, LBNL, and others concerning the energy use patterns and DR potential for California industry.

The goal of the DRRC industrial research is to facilitate deployment of industrial Auto-DR that is economically attractive and technologically feasible. Automating demand response will make DR:

- More visible by providing greater transparency through two-way end-to-end communication that allows Internet tracking of the receipt of DR signals from end-use customers;

- More repeatable, reliable, and persistent because the DR signals trigger fully automated controls strategies that are "hardened" and pre-programmed into facility's software and hardware;

\footnotetext{
4 Statewide program participation for industrial and agricultural customers in Evaluation of 2005 Statewide Large
} Nonresidential Day-Ahead and Reliability Demand Response Programs, Quantum 2006 
- More affordable because automation can help reduce labor costs associated with manual DR strategies initiated by facility staff and can be used for long-term.

During the first year of study, the DRRC Industrial Team began to develop the broad outlines of a methodology for successful implementation of Auto-DR. While significantly more work needs to be done, the potential for industrial Auto-DR seems substantial and attainable. We envision a situation within the next two or three years in which specific sectors will be targeted with a menu of potential Auto-DR strategies, enabled by the rapid growth of industrial controls to support these strategies.

\subsubsection{Research Scope}

The 2006-2007 DR industrial research considered both near-term needs to facilitate industrial Auto-DR for the summer of 2007 and as well as longer term research. This longer-term study is focused on five key research questions.

\section{Key Research Questions}

1. Where is the potential to shed or shift electricity use in industry?

- Which sectors have the greatest potential to shed or shift during peak periods?

- Have these sectors been active in reliability programs or identified in audits?

2. What is the functional capability of specific industries to implement Auto-DR?

- What are the control gaps and the associated cost of implementing Auto-DR?

- Of sectors identified as having Auto-DR potential, which offer the most cost-effective implementation opportunities?

3. What are the market trends in industrial controls that support Auto-DR?

- Do advances in control technologies make specific sectors or systems attractive candidates for Auto-DR?

- What are the technology gaps that might benefit from public R\&D?

4. What are the market and operational barriers to the implementation of reliability and price-responsive industrial DR?

- Do industrial energy managers understand economic and societal benefits of DR

- What roles do price and incentives have in the decision making process?

- What are the areas tension between DR and industrial plant schedules?

5. What is the role of industrial Auto-DR in the state's goal to provide reliable and climate-friendly electricity at a reasonable cost to CA consumers?

- Is there "migration potential” for DR strategies in promoting industrial load management and energy efficiency in industrial facilities? 
Research to date has included:

- A literature search on prior experience (mainly in California and New York) with industry participation in interruptible demand response programs as described in Section 1.2.4.1.

- Preliminary analysis of electricity use and electricity use patterns in California industry, as described in Section 1.2.4.2

- A draft Industrial Demand Response Strategic Roadmap, as described in Section 2.1

- Creation and analysis of the Utility Industrial Integrated Audit Demand Response Database, as described in Section 2.2.

- An analysis of the potential barriers to industrial implementation of Auto-DR, including additional insights from 2007 field work, as described in Section 2.3

- Collaboration in PG\&E territory on Auto-DR recruitment and implementation for the 2007 season, as described in Section 2.4

- A summary of the results of scoping studies undertaken to gain a better understanding of sector-specific DR opportunities and barriers in the food processing and semiconductor industries, as described in Section 2.5.

- Analysis of sub-metering to monitor DR at six industrial facilities over a period of two years, as described in Section 2.6.

\subsubsection{Benefit to California}

This report provides a summary of research findings to date and plans for future research on industrial demand response. Demand response also holds promise as an attractive enhancement of the control strategies introduced into industrial facilities for load management. ${ }^{5}$ The enhancement of these load management control strategies for Auto-DR could, in turn, make visible through measurement and analysis, the true energy efficiency potential to be realized in many facilities through cost-effective operational changes. This integrated approach that optimizes both the timing and amount of electricity to meet production needs describes the energy-efficient California industrial facility of the future.

\subsubsection{Report Organization}

This section describes the context, rationale, and potential for industrial demand response; program goals and objectives; research scope and key questions; previous research, industrial energy usage patterns, and terms and concepts for industrial Auto-DR strategies.

Section 2 describes the program activities undertaken in the first year, including:

- the industrial demand response roadmap,

\footnotetext{
${ }^{5}$ Customer actions intended to limit the amount of electricity used at a particular time, particularly to avoid demand charges
} 
- development and analysis of an industrial demand response database from the utility integrated audits,

- identification and analysis of barriers to implementation of Auto-DR,

- collaboration on recruitment and implementation,

- the results of submetering at selected sites, and

- summary results from scoping studies to date.

Section 3 summarizes key findings from these activities.

Section 4 identifies promising areas for future research.

Section 5 provides conclusions.

Section 6 lists references.

Supporting information is included in the Appendices A-G.

\subsubsection{Previous Research}

\subsubsection{Industrial Demand Response}

To support the PIER DRRC industrial demand response research tasks and plans, a literature search was conducted to evaluate the key research questions on industrial DR and state of the art knowledge. A complete list is included in Section 6, References. In addition to a number of publications from the DRRC that provided a valuable foundation for this research, a few key studies with relevance to industrial DR are discussed here:

- Quantum Consulting and Summit Blue Consulting. 2006. Evaluation of 2005 Statewide Large Nonresidential Day-Ahead and Reliability Demand Response Programs, prepared for Southern California Edison Company and Working Group 2 Measurement and Evaluation Committee.

This report includes a good overview of manual industrial DR programs for large nonresidential customers in California, including terminology, participation, barriers, recommendations, and submetering results. Of particular interest is the summary of submetering results, which is analyzed in more depth in Section 2.6.

- EPRI (Electric Power Research Institute), 2005. Demand Response Analysis and Tool Development for Industrial, Agricultural and Water (IAW) Energy Users. Sacramento, CA: California Energy Commission

Using a telephone survey, in-depth interviews were conducted with a small sample of energy managers of the following sectors: cement, electronics, industrial gases, metal casting, petroleum refining, pulp and paper, oil and gas refining, water agencies, agricultural production, and food processing. Key findings include:

1. Reliability is a profoundly more potent motivator than energy cost for DR;

2. The packaging of DR offerings is perceived as inadequate;

3. A business's profit margin can affect their view of economically-driven DR;

4. DR creates a conflict of interest with other energy cost reduction measures; 
5. DR that relies on shedding or shifting manufacturing loads is likely to face a stiff, uphill battle.

While acknowledging that additional research is required, the initial results of our first year would seem to support the concept that demand response can actually lead to greater energy efficiency and that industry will, under certain circumstances in selected sectors, voluntarily agree to a production shift or shed. Although much more data is needed, these decisions appear to hinge on the quality of the business proposition versus the risk.

- Goldman, C. and N. Hopper, O. Sezgen, M. Moezzi, R.Bharvirkar, B.Neenan, D.Pratt, P. Cappers, and R.Boisvert. 2004. Does Real-Time Pricing Deliver Demand Response? A Case Study of Niagara Mohawk's Large Customer RTP Tariff. LBNL-54974

Examines how Niagara Mohawk (NY) large customers adapted to real time pricing, with government/educational customers the most responsive group, industry second most responsive, and commercial customers, third. A key finding was that while industrial customers have lower responses to day-ahead prices, the New York Independent System Operator DR programs significantly boost industrial participants' price response when events are called. Also of note was the seeming lack of correlation between installation of DR-enabling technology and subsequent program participation.

- York, Dan and Martin Kushler. 2005. Exploring the Relationship Between Demand Response and Energy Efficiency: A Review of Experience and Discussion of Key Issues. American Council for an Energy-Efficient Economy, Washington, DC Report \# U052.

This report examines the relationship between energy efficiency and demand response (not limited to industrial), especially areas for potential conflict. The authors acknowledge that there is little published research in this area on how demand response affects energy use during off-peak periods as well as energy use and energy efficiency more generally. The report concludes that energy efficiency programs achieve demand reduction at a higher cost than demand response programs, but could be considered as providing baseline levels of peak-demand reduction or "permanent demand response". There is an assumption of loss of service from demand response that is not attributed to energy efficiency. On the other hand, the authors use NYSERDA's programs as evidence that "energy efficiency and demand-response objectives can be combined into a single package.” Of interest in this report is the recognition of an as yet unrealized potential for advanced building systems to be used as "an active management tool" - primarily due to the lack of economic incentives and human resources.

\subsubsection{Industrial Energy Usage Patterns}

This section describes preliminary analysis conducted on industrial consumers of electricity by industry type for their potential to participate in demand response (DR) programs, taking into consideration such factors as the share of the total industrial consumption of purchased electricity and what is currently known about the technical or economic potential of these industries to execute DR measures. 
A particularly useful document for this work is the California Industrial Existing Construction Energy Efficiency Potential Study CALMAC Study ID: PGE2052.01 (KEMA 2006). This report identifies three types of energy efficiency potential for California industries: technical, economic, and achievable program potential. The data included in this report are helpful in developing an understanding of the energy use patterns and potential for California industry.

\section{Manufacturing Industries}

Table 1 ranks all California industries by their consumption of purchased electricity using 2004 data from the California Energy Commission. Information on self-generation is included, but for the purposes of DR, it is the electricity delivered from the grid that matters. The industries have been grouped at the four-digit level of the North American Industrial Classification System (NAICS). Industries have been further disaggregated to the five- or six-digit level for categories that are highly heterogeneous within the four-digit classification or where one specific industry accounts for a particularly large proportion of the four-digit total.

The table also shows an estimate of average MW demand by these industries. The estimate is derived from total consumption using an assumed 24-hour daily production schedule and an 80 percent average capacity utilization factor. This assumption may underestimate the demand of highly seasonal industries, such as wineries and food canning and freezing facilities. The top ten largest users of electricity at the four-digit level are discussed in more detail below. Where relevant, a comparison is made between the results of these analyses and the conclusions of the 2005 report commissioned by the CEC from EPRI. 
Table 1. Electricity Used by California Manufacturing Industries, 2004

\begin{tabular}{|c|c|c|c|c|c|}
\hline $\begin{array}{l}\text { NAICS } \\
\text { Code }\end{array}$ & NAICS Category & $\begin{array}{l}\text { Purchased } \\
\text { MWh }\end{array}$ & $\begin{array}{l}\text { Share Mfg } \\
\text { Purchased }\end{array}$ & $\begin{array}{l}\text { Self-Gen } \\
\text { MWh }\end{array}$ & $\begin{array}{l}\text { Purchased } \\
\text { MW }^{\text {a }}\end{array}$ \\
\hline 3344 & Semicndctrs \& Elctrncs & $2,633,090$ & $8.1 \%$ & & 375.7 \\
\hline 334413 & Semicndctrs \& Related & $1,792,902$ & $5.5 \%$ & & 255.8 \\
\hline 3261 & Plastic Prdts & $1,942,201$ & $6.0 \%$ & & 277.1 \\
\hline 3241 & Petroleum \& Coal Prdts & $1,542,391$ & $4.8 \%$ & $5,212,623$ & 220.1 \\
\hline 3251 & Basic Chemicals & $1,406,927$ & $4.4 \%$ & 702,408 & 200.8 \\
\hline 32512 & Indl Gases & $1,318,637$ & $4.1 \%$ & 170,465 & 188.2 \\
\hline 3341 & Computers \& Periphs & $1,199,963$ & $3.7 \%$ & & 171.2 \\
\hline 3364 & Aerospace Prdts & $1,115,034$ & $3.4 \%$ & & 159.1 \\
\hline 336411 & Aircraft Manufacturing & 460,641 & $1.4 \%$ & & 65.7 \\
\hline 3121 & Beverages & $1,108,782$ & $3.4 \%$ & & 158.2 \\
\hline 31211 & Soft Drinks \& Ice & 307,454 & $1.0 \%$ & & 43.9 \\
\hline 31212 & Breweries & 261,101 & $0.8 \%$ & & 37.3 \\
\hline 31213 & Wineries & 531,865 & $1.6 \%$ & & 75.9 \\
\hline 3273 & Cement \& Concrete & $1,096,399$ & $3.4 \%$ & 131,090 & 156.4 \\
\hline 32731 & Cement & 732,087 & $2.3 \%$ & 131,090 & 104.5 \\
\hline 3115 & Dairy Prdts & $1,046,196$ & $3.2 \%$ & & 149.3 \\
\hline 311513 & Cheese & 498,635 & $1.5 \%$ & & 71.2 \\
\hline 3114 & Canned \& Frzn Foods & 912,000 & $2.8 \%$ & & 130.1 \\
\hline 311421 & Frt \& Vegtbl Canning & 389,159 & $1.2 \%$ & & 55.5 \\
\hline 3342 & Communication Eqpt & 943,187 & $2.9 \%$ & & 134.6 \\
\hline 3254 & Pharm \& Medicines & 810,562 & $2.5 \%$ & & 115.7 \\
\hline 3345 & Nav \& Contrl Instrmnts & 836,715 & $2.6 \%$ & & 119.4 \\
\hline 3222 & Paper Prdts & 752,872 & $2.3 \%$ & & 107.4 \\
\hline 3272 & Glass & 746,146 & $2.3 \%$ & & 106.5 \\
\hline 3279 & Oth Nonmetall Minrls & 707,426 & $2.2 \%$ & & 100.9 \\
\hline 3231 & Printing & 705,239 & $2.2 \%$ & & 100.6 \\
\hline 3118 & Bakeries \& Tortillas & 615,210 & $1.9 \%$ & & 87.8 \\
\hline 3323 & Structural Metals & 578,981 & $1.8 \%$ & & 82.6 \\
\hline 3116 & Meat Packing & 569,358 & $1.8 \%$ & 61,203 & 81.2 \\
\hline 3391 & Medical Eqpt & 515,781 & $1.6 \%$ & & 73.6 \\
\hline 3329 & Oth Fab Metal Prdts & 487,471 & $1.5 \%$ & & 69.6 \\
\hline 3328 & Coating \& Engraving & 400,338 & $1.2 \%$ & & 57.1 \\
\hline 3332 & Indl Machinery & 360,654 & $1.1 \%$ & & 51.5 \\
\hline 3119 & Other Foods & 324,901 & $1.0 \%$ & & 46.4 \\
\hline 3324 & Boilrs, Tanks, Contnrs & 316,848 & $1.0 \%$ & & 45.2 \\
\hline
\end{tabular}

The largest industrial user of purchased electricity in California is Semiconductors and Other Electronic Components. The manufacture of semiconductors alone accounts for nearly 70 percent of the four-digit total. Semiconductor and electronic component manufacturing generally runs on a relatively constant annual and time of day production schedule.

Semiconductor electricity consumption is dominated by a few large plants in California. Due to the high margin of the products produced, it is unlikely that these facilities would engage in any measures that would affect core production. However, the EPRI report states that portions of loads used for R\&D activities (e.g., test runs of new chip designs), selected support loads in manufacturing, and loads that serve administrative areas could be available for curtailment in 
response to high prices. The EPRI report further notes that electricity comprises 40 to 60 percent of the operating costs for semiconductor manufacturing. Facility energy managers tend to be knowledgeable and receptive to technical innovation. Anecdotal information collected during 2007 Auto-DR site recruitment appears to support these statements.

The next largest user of purchased electricity at the four-digit level is the manufacture of plastic products. This includes products such as bags, pipes, plastic sheets, foam, and bottles. Energy consumption is fairly evenly distributed through this subsector, except for the largest six-digit subsector, which is All Other Plastic Products. As one of the larger electricity consumers in California, some in-depth assessment of potential DR measures in this industry should be conducted, perhaps in cooperation with the Society of the Plastics Industry, which has previously collaborated with the U.S. Department of Energy on energy efficiency studies. ${ }^{6}$

The largest total user of manufacturing electricity (purchased and self-generated) in California is Petroleum and Coal Products, a sector that is dominated by petroleum refineries and includes more than 1.5 MWH of purchased electricity and 5.2 MWh of self generated electricity. The EPRI report describes petroleum refining as a "fair" candidate for DR, but estimates a DR potential of only 7.6 MW, despite an estimate of over $900 \mathrm{MW}$ of coincident peak demand, which would seem to include on-site generation. However, 7.6 MW is still only 3.5 percent of our estimated demand of $220 \mathrm{MW}$, and it certainly seems possible that with more in-depth analysis opportunities for greater reductions could be identified. ${ }^{7}$

Basic Chemicals accounts for 4.4 percent of purchased manufacturing electricity, of which Industrial Gases represents the largest share. This sector was rated as a "good" candidate for DR in the EPRI report. The authors point out that industrial gas manufacturers have considerable experience with interruptible rates and can reschedule processes relatively easily. EPRI estimates an achievable curtailable load of $131 \mathrm{MW}$. While this is based on a higher estimated coincident load of $240 \mathrm{MW}$, it still represents a very high share of load, about 55 percent. Sheds of this magnitude are supported by the results of the 2007 DRRC Industrial Team collaboration. This is a sizeable DR resource in a concentrated industry where outreach to a relatively small number of energy managers would help to enable a significant DR resource. See Section 2.4 Collaboration for a further discussion of DR experience with this sector.

The fifth largest user of purchased manufacturing electricity is Computers and Peripheral Equipment. Unlike the Semiconductors and Electronic Components industry, this industry is composed of the facilities that assemble components into final products. This industry is included in the broader "electronics industry" categorization used in the EPRI report. As a large user of electricity, this industry also warrants a more in-depth assessment of potential DR measures.

\footnotetext{
${ }^{6}$ Improving Energy Efficiency in US Manufacturing Plants, 2005, prepared by the Society of the Plastics Industry and the U.S. Department of Energy, DOE/GO 102005-2111

http://www1.eere.energy.gov/industry/bestpractices/pdfs/plastics_report.pdf

${ }^{7}$ A resource for developing a more in-depth understanding is:

Worrell, Ernst and Christine Galitsky. 2004. Profile of the Petroleum Refining Industry in California prepared for the California Industries of the Future Program. LBNL-55450 http://ies.lbl.gov/iespubs/55450.pdf
} 
Of the next five largest purchased electricity users, the EPRI report includes all except for Aerospace Products. Electricity consumption is fairly evenly split among the six six-digit level subsectors of Aerospace Products, although Aircraft Manufacturing consumes the largest share at about 40 percent of electricity in this industry. With a limited number of sites to approach and a good track record in energy efficiency, this industry may also represent a promising source DR potential and deserves further research to determine DR amenable loads. ${ }^{8}$

The EPRI report covers the "Cement” portion of Cement \& Concrete Products as well as food processing - broadly defined to include fruit and vegetable preservation, dairy products, and beverages. EPRI characterizes cement as a "good" DR candidate with an estimated achievable DR potential of 39 MW based on an estimated coincident peak demand of 212 MW. A cement industry respondent to EPRI's survey felt that most of the DR potential could be achieved by rescheduling certain electricity-intensive support operations. Anectodal evidence from the industry would seem to support this statement.

In contrast, EPRI describes the food processing industry as a "fair" candidate for DR. The authors note that these industries are very concerned about interruptions that could result in product spoilage and that survey respondents from this industry indicated that only a small share of this industry's load would be available for DR. For fruit and vegetable processing, in particular, peak production coincides with statewide peak electricity usage. A scoping study to further assess DR potential in food processing industries is summarized in Section 2.6. However, this study is based on survey results and more basic technical research is needed, particularly for specific subsectors. Based on their relative share of the load, wineries, breweries, and cheese producers should be more intensively targeted for DR research and demonstration. A few wineries have already received DR audits from PG\&E contractors and these audits are being analyzed to determine the most promising DR measures.

Cold storage associated with fruit and vegetable processing may also offer DR potential. In addition to the manufacturing industries listed above, refrigerated warehouses consumed another 1,245,811 MWh with 722,988 GWh in the NAICS 4931 category (warehousing and storage) and the rest in NAICS 4244 (grocery wholesale). Due to the relative homogeneity of the technology and the relative ease of implementing DR, utilities should focus on recruiting sites in these sectors. In the section of the 2005 Evaluation Report of DR programs that reviewed the experience with sub-metering of six industrial facilities, adjustment of cold storage was the principal strategy used at four sites (Quantum Consulting, 2006). Two of these sites used this strategy quite successfully, and this would appear to be an easily replicable strategy that could contribute significantly to DR in California. A more detailed analysis of which products have the most tolerance for temporary temperature increases and the amount of cold storage space dedicated to those products would help to refine the targeting of facilities in these NAICS codes.

\footnotetext{
${ }^{8}$ This statement seems to be supported by feedback received from several leading companies in Nov-Dec 2007 as part of the 2009-2020 Statewide Energy Efficienct Strategic Plan process - see the industry sector under http://www.californiaenergyefficiency.com
} 


\subsection{Terms and Concepts for Industrial Auto DR Strategies}

The demand-side management (DSM) framework presented in Table 2. Demand Side

Management Framework for Industrial Facilities provides three major areas for changing electric loads in industrial buildings: energy efficiency (for steady state load minimization); peak load management (for daily operations); and DR (for event driven dynamic peak load reduction).

Table 2. Demand Side Management Framework for Industrial Facilities

\begin{tabular}{|l|l|l|l|}
\hline \multirow{2}{*}{ Motivation } & \multicolumn{1}{|c|}{$\begin{array}{c}\text { Efficiency and } \\
\text { Conservation } \\
\text { (Daily) }\end{array}$} & $\begin{array}{c}\text { Deak Load Management } \\
\text { (Daily) }\end{array}$ & \multicolumn{1}{c|}{$\begin{array}{c}\text { Demand Response } \\
\text { (Dynamic } \\
\text { Event Driven) }\end{array}$} \\
\cline { 2 - 5 } & $\begin{array}{l}\text { Envility Bill Savings } \\
\text { Enmental Protection }\end{array}$ & $\begin{array}{l}\text { TOU Savings } \\
\text { Demand Charge Savings } \\
\text { Grid Protection }\end{array}$ & $\begin{array}{l}\text { Price } \\
\text { Reliability } \\
\text { Emergency } \\
\text { Grid Protection }\end{array}$ \\
\hline Operations & $\begin{array}{l}\text { Efficient Production and } \\
\text { Support Equipment \& }\end{array}$ & Low Power Design & $\begin{array}{l}\text { Dynamic Control Capability for } \\
\text { Production and Support } \\
\text { Systems }\end{array}$ \\
& $\begin{array}{l}\text { System Operations } \\
\text { Optimized Production } \\
\text { System Operations }\end{array}$ & $\begin{array}{l}\text { Demand Limiting } \\
\text { Demand Shifting }\end{array}$ & $\begin{array}{l}\text { Demand Shedding } \\
\text { Demand Shifting } \\
\text { Demand Limiting }\end{array}$ \\
\hline Initiation & Local & Local & Remote \\
\hline
\end{tabular}

- Energy Efficiency: Energy efficiency and conservation can lower energy use to provide the same level of service. Driven by the desire for utility bill savings and environmental protection, energy efficiency measures permanently reduce peak load by reducing overall consumption. This is typically done in industrial facilities by installing energy efficient equipment and facilitating efficient operations.

- Daily Peak Load Management: Daily peak load management is the practice of operating a facility to reduce time-of-use or peak demand charges. Typical peak load management methods include demand limiting and demand shifting. Demand limiting refers to shedding loads when pre-determined peak demand limits are about to be exceeded. Loads are restored when the demand is sufficiently reduced. This is typically done to flatten the load shape when the pre-determined peak is the monthly peak demand. Demand shifting is shifting the loads from peak times to off-peak periods. Figure 2 displays the typical demand profile of an industrial facility employing these methods. While not always the case, notification requirements, workforce considerations, and supplier schedules often result in load shifts at industrial facilities occurring later, rather than earlier, in a 24 hour period. 
- Demand Response: Demand response refers to the modification of customer electricity usage at times of peak usage in order to help address system reliability, reflect market conditions and pricing, and support infrastructure optimization or deferral. Demand response programs may include dynamic pricing and tariffs, price-responsive demand bidding, contractually obligated and voluntary curtailment, and direct load control or equipment cycling. DR methods, such as demand limiting and shifting can be utilized when the economics and reliability issues are predicted and communicated to each site in advance. Demand shedding is the dynamic temporary reduction, or curtailment of peak load through building services or process load changes.

The bottom row of Table 2 labeled "Initiation" indicates if the activity is a result of a local facility manager motivation or a remote requirement set forth by the facility or an outside entity, such as a utility.

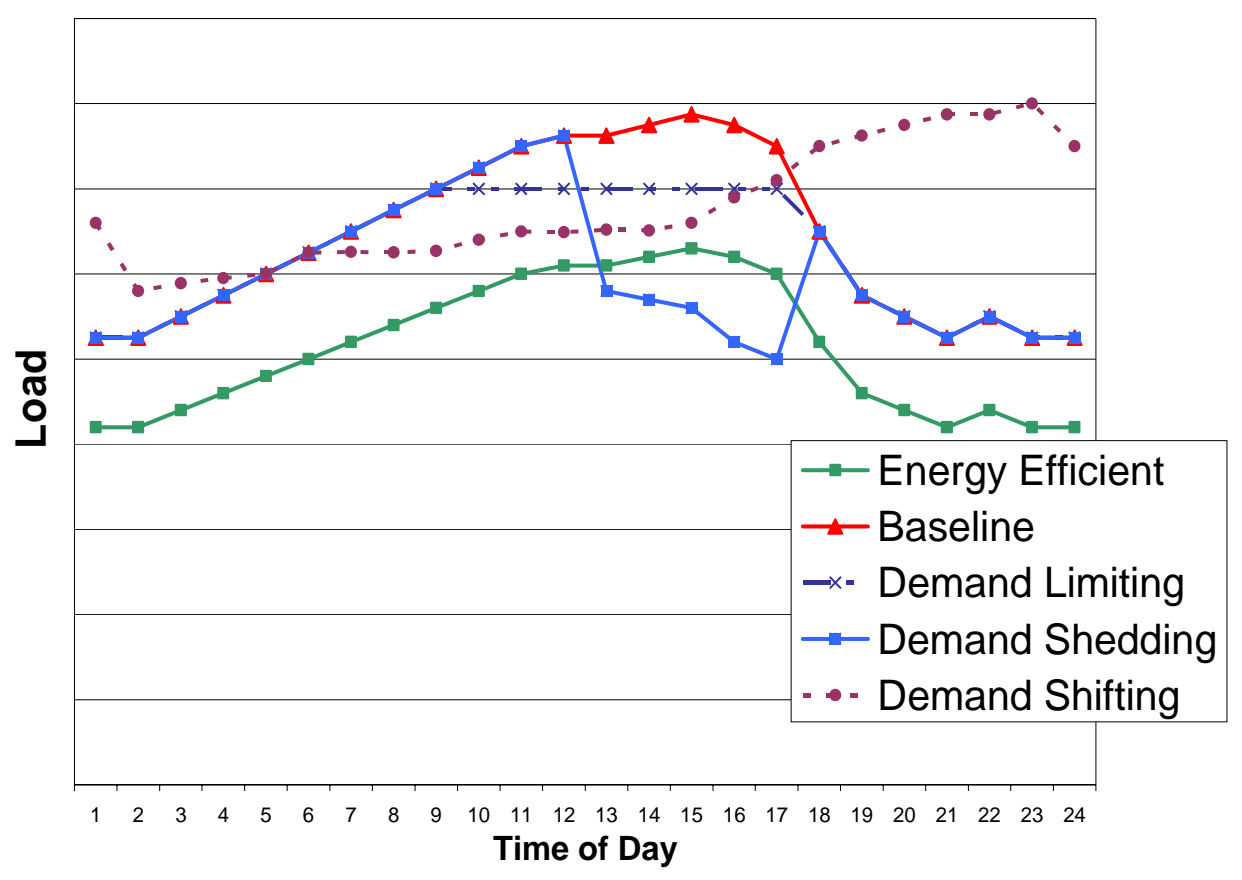

Figure 2. Demand Profile of Various Demand Response Methods in Industrial Facilities

\section{Automated Demand Response (Auto-DR) Technology Overview}

The technology used for Auto-DR programs for industrial facilities in 2007 originated from initial conceptual design in 2002 at LBNL. Auto-DR is a fully automated demand response system using Client/Server service oriented architecture (SOA) and is intended to replace laborintensive manual and semi-automated DR. Before 2007, Auto-DR was primarily used for commercial buildings for HVAC and lighting end-use loads using signals between utilities and customer facilities based on communication technology standards that integrated with third-party proprietary controls and communications software. The essential elements of an Auto-DR system are shown in Figure 3 and include: 
- Demand Response Automation Server (DRAS) for Auto-DR based on the interoperable, standard-based architecture using Web Services (WS);

- Client \& Logic with Integrated Relay (CLIR) box, WS software client, etc., customized for industry requirements, providing flexibility for participation; and

- Energy Management Control Systems, Energy Information Systems (EMCS/EIS) or other forms of control systems with pre-programmed DR strategies are used within the industry.

Auto-DR systems are built using eXtensible Markup Language (XML) and Simple Object Access Protocol (SOAP) based secure Web Service Oriented Architecture (SOA) for platformindependent, interoperable systems that use low-bandwidth Transmission Control Protocol and Internet Protocol (TCP/IP) Internet connections. This Auto-DR technology has been used for PG\&E, SCE CPP and/or DBP Auto-DR programs during 2007 and is scalable to accommodate California's goal of dynamic-pricing and real-time-pricing (RTP) models.

As shown in Figure 3, the steps involved in the Auto-DR process during a DR event are:

1. The Utility or ISO defines DR event and price/mode signals are sent to the DRAS;

2. $\quad$ DR event and price services published on the DRAS;

3. $\quad$ DRAS Clients (CLIR or WS) request real-time event data from the DRAS every minute;

4. $\quad$ Customized pre-programmed DR strategies determine action based on event price/mode;

5. Facility Energy Management Control Systems (EMCS) or related controls carry out load reduction based on DR event signals and strategies.

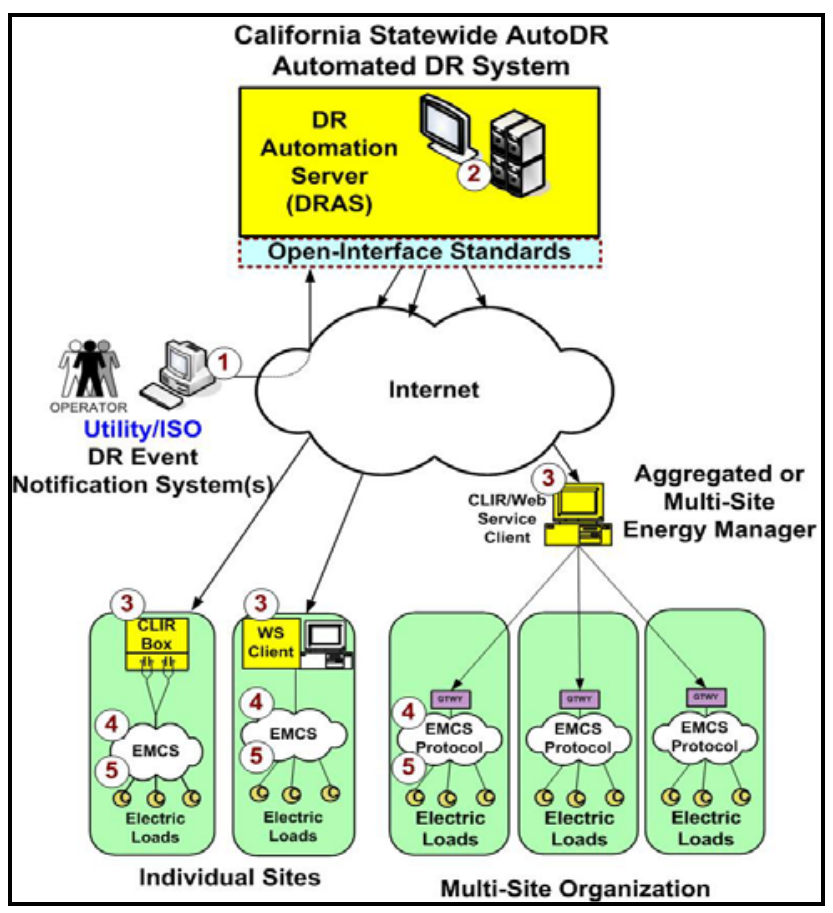

Figure 3. Generic Automated DR Open-Interface Standard Architecture 


\subsection{Program Activities}

\subsection{Industrial Demand Response Strategic Research Roadmap}

The first task of the Industrial Auto Demand Response Program was to develop an Industrial Demand Response Research Roadmap. The purpose of the roadmap is to provide guidance for research on methods to reduce peak electric demand in the industrial sector through an automated demand response. The roadmap identifies technical, educational and economic barriers to successful industrial Auto-DR and methods for overcoming these barriers. The research combines analysis with empirical results from field experience and theoretical process control. The initial draft Roadmap was informed by several resources, including:

- CEC's Demand Response Analysis and Tool Development for Industrial, Agricultural, and Water (IAW) Energy Users;

- Evaluation of 2005 Statewide Large Nonresidential Day-Ahead and Reliability Response Programs;

- U.S. DOE Energy Footprints;

- Results of sub-metering demand response demonstration projects;

- Original research by DRRC to begin to characterize California's industrial load by process within each industry by comparing the results of estimated electricity usage and coincident peak demand as described in Section 1.5.2; and

- $\quad$ CEC/PIER Industrial End Use Energy Efficiency strategic planning process.

Initial development included work with CEC staff and the DRRC to synthesize and integrate findings concerning the demand response potential for California industry. The draft report is included in Appendix A.

Future work on the Research Roadmap will include the following additional resources through a Technical Advisory Group:

- $\quad$ Results from ongoing utility-based demand response activities, including Auto-DR implementation experience;

- Input from concerned stakeholders, especially relating to industrial control technologies and strategies; and

- Input from contractors, especially those undertaking sector-specific analyses and studies and DR tool development.

\subsection{Utility Industrial Integrated Audit Demand Response Database}

\subsubsection{Purpose}

California's investor-owned utilities (IOUs) have been offering energy efficiency audits to large service sector and industrial customers for many years as part of their demand side management activities. Historically, these audits have focused exclusively on energy efficiency (EE) measures, but increasing interest in demand response has led the IOUs to ask auditors to include information on both EE and DR opportunities. These integrated audits have only recently begun to incorporate DR recommendations, with few audits performed prior to 2005 containing DR recommendations. 
The DRRC launched the development of a DR audit database to synthesize findings from the integrated audits across the state. Price-responsive DR strategies are much less developed in the industrial sector due to the heterogeneity of energy uses and the demands of maintaining production schedules. The DR audit database has an initial focus on the integrated audits performed in manufacturing facilities in order to promote greater uptake of DR capacity in the industrial sector. The DR audit database allows researchers at the DRRC to analyze the results according to a variety of criteria such as industry classification, measure type, and utility provider.

\subsubsection{Data collection methodology}

Due to the confidentiality of the data from the utilities' integrated audits, the DRRC reached an agreement to have a DRRC Industrial Team member review the audits at the utility offices and record notes in a spreadsheet. The subject company names were redacted from the review documents. Using this methodology, DRRC was able to obtain 103 audit records from Pacific Gas \& Electric (PG\&E), 85 audit records from Southern California Edison (SCE) and 19 records from San Diego Gas and Electric (SDG\&E).

\subsubsection{Taxonomy}

The audit database is designed to structure the integrated audit data to allow analysis for AutoDR potential by North American Industry Classification System (NAICS) or plant type, by shift or shed strategy for both production and supporting systems, and by technology or measure. This was accomplished by developing a draft structure based on the Team's industrial energy efficiency and commercial demand response experience. This preliminary structure evolved during a testing and refining process as it was populated with data. The current structure is in Microsoft Access and is sufficiently flexible to be modified for additional categories as the need arises.

There are two main tables: “Audit Info" and "Measure” that are linked together through a one-tomany relationship. Each record (or Audit ID) in the Audit Info table is linked to a maximum of six demand response measures that are listed in the Measure table. A diagram of these relationships is illustrated in Figure 4. A detailed list of database fields can be found in Appendix B.

Since NAICS designations were not provided in the original data, each audit record was evaluated by the Team and assigned a category based on the plant description. Although the energy efficiency data associated with each audit was not disaggregated by measure as part of this initial process, its integrity has been preserved for future disaggregation and analysis, if desired. 


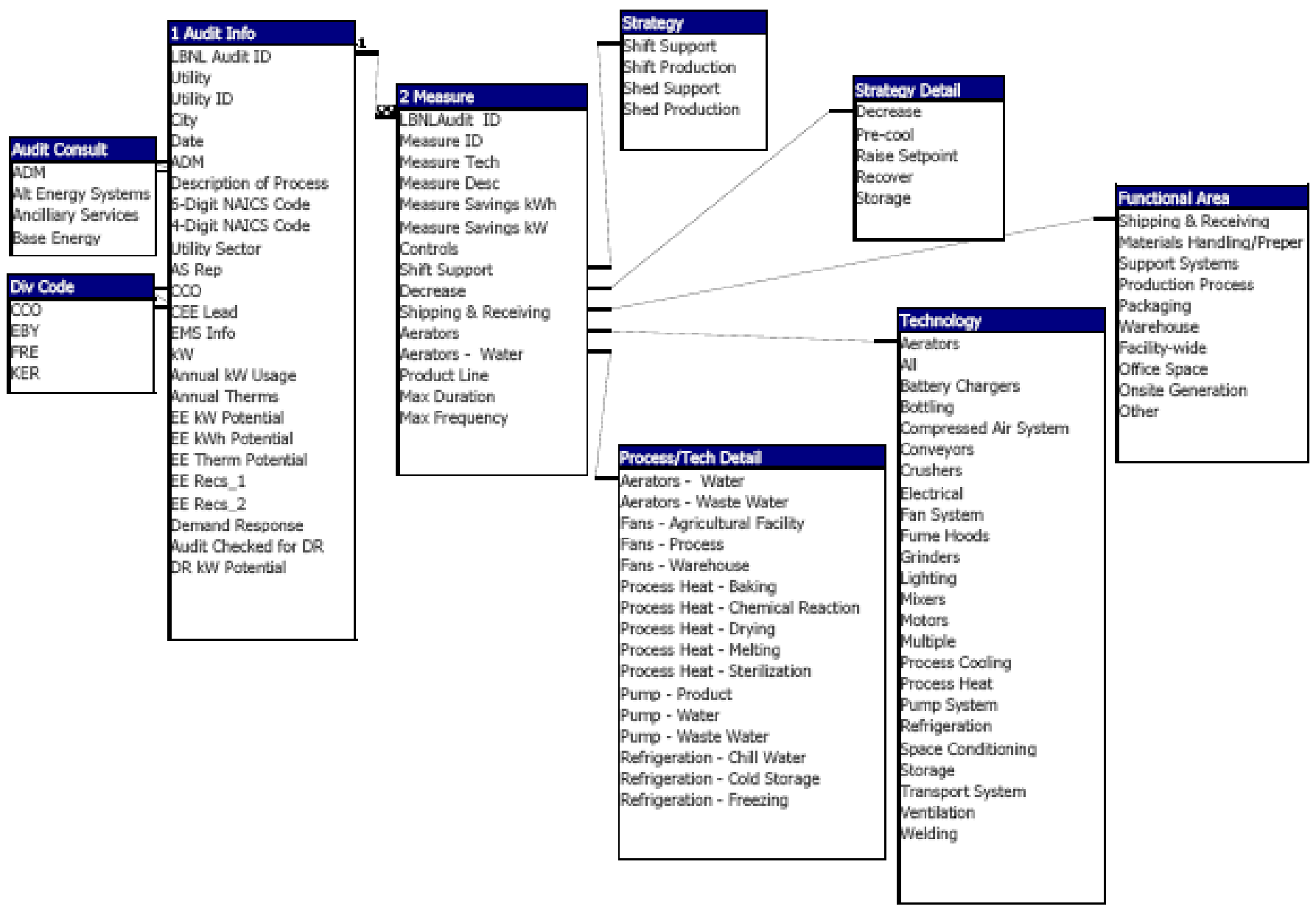

Figure 4. Industrial Demand Response Audit Database Taxonomy 


\subsubsection{Analysis}

Analyses were conducted of the 207 records in the Industrial Demand Response Audit Database. The highlights of these analyses are captured in the series of summary tables in Tables 3-8. A complete version of the data in Table 3 and Table 4 is included in Appendix C.

Table 3 presents the average DR potential by plant type and the sum for each plant type category. Where the sample includes only one plant of that type, the average and sum will be the same. Table 4 uses the 4-digit NAICS categories assigned by plant type to develop a slightly more aggregated picture for the top 25 categories by average $\mathrm{kW}$ demand response potential. In Table 5, the NAICS categories in the top 25 by average $\mathrm{kW}$ demand response potential for the Industrial Demand Response Audit Database are compared to the top 25 manufacturing industries by electricity use from Table 1 . Given the relatively small sample size, there are a significant number of matches -9 out of 25 . These categories may warrant further study.

Leading opportunities for production shifts are conveyors, all systems, pump systems, and electrical. For production sheds, the leading opportunities are all systems (stop production), finishing, process cooling, and pump systems. For supporting systems, the leading opportunities to shift load are space conditioning, motors, process cooling, and storage. The leading shed opportunities are aerators, multiple systems, electrical, and compressed air.

Table 6 identifies and quantifies the production shift/shed potential for specific strategies; Table 7 does the same for supporting systems. In Table 8, the specific technologies involved in the shift and shed strategies are identified. 
Table 3. Industrial Demand Response Potential by Plant Type (Top 25 by Average kW); n=207

\begin{tabular}{|c|c|c|c|c|}
\hline Sum of DR kW Potential & & DR kW Potential & & \\
\hline Description of Process & Total & Description of Process & Sum & Ave \\
\hline Lumber products, fiber board & 3504 & Lumber products, fiber board & 3504 & 3504 \\
\hline Federal R\&D & 2320 & Federal R\&D & 2320 & 2320 \\
\hline Olive Processing Plant & 1979 & Olive Processing Plant & 1979 & 1979 \\
\hline Quarrying /processing of mineral rock \& sand aggregate & 2582 & Quarrying /processing of mineral rock \& sand aggregate & 2582 & 1291 \\
\hline Envelopes & 1133 & Envelopes & 1133 & 1133 \\
\hline Milk, water, eggnog, juice & 933 & Milk, water, eggnog, juice & 933 & 933 \\
\hline Agricultural irrigation & 895 & Agricultural irrigation & 895 & 895 \\
\hline Aircraft equipment & 890 & Aircraft equipment & 890 & 890 \\
\hline Industrial gases & 1759 & Industrial gases & 1759 & 880 \\
\hline Makes PVC pellets or cubes & 870 & Makes PVC pellets or cubes & 870 & 870 \\
\hline Waffle Food Process & 868 & Waffle Food Process & 868 & 868 \\
\hline Cotton clean and bale & 834 & Cotton clean and bale & 834 & 834 \\
\hline Strawberry Processing, Freezing & 817 & Strawberry Processing, Freezing & 817 & 817 \\
\hline Bakery bread, buns & 749 & Bakery bread, buns & 749 & 749 \\
\hline Fresh water delivery & 733 & Fresh water delivery & 733 & 733 \\
\hline Fluid control equipment & 657 & Fluid control equipment & 657 & 657 \\
\hline Batteries & 1750 & Batteries & 1750 & 583 \\
\hline Unknown [not identified in audit] & 582 & Unknown [not identified in audit] & 582 & 582 \\
\hline Distribution warehouse for food products & 523 & Distribution warehouse for food products & 523 & 523 \\
\hline Ground walnut shells & 490 & Ground walnut shells & 490 & 490 \\
\hline Fruit drier, processors & 449 & Fruit drier, processors & 449 & 449 \\
\hline Clay Products, Building Materials & 415 & Clay Products, Building Materials & 415 & 415 \\
\hline Wastewater treatment plant & 791 & Wastewater treatment plant & 791 & 396 \\
\hline Poultry Processor & 744 & Poultry Processor & 744 & 372 \\
\hline Food packaging & 326 & Food packaging & 326 & 326 \\
\hline
\end{tabular}


Table 4. Industrial Demand Response Potential by 4-Digit NAICS (Top 25 by Average kW); n=207

\begin{tabular}{|c|c|c|c|}
\hline & & DR kW Po & tential \\
\hline \begin{tabular}{l|} 
4-Digit \\
NAICS Code
\end{tabular} & NAICS Description, 2007 & Sum & Ave \\
\hline 3211 & Sawmills and Wood Preservation & 3598 & 1799 \\
\hline 2123 & Nonmetallic Mineral Mining and Quarrying & 2582 & 1291 \\
\hline 3222 & Converted Paper Product Manufacturing & 1133 & 1133 \\
\hline 5417 & Scientific Research and Development Services & 2693 & 898 \\
\hline 3114 & Fruit and Vegetable Preserving and Specialty Food Manufacturing & 4403 & 881 \\
\hline 3331 & Agriculture, Construction, and Mining Machinery Manufacturing & 1729 & 865 \\
\hline 3251 & Basic Chemical Manufacturing & 1868 & 623 \\
\hline 3359 & Other Electrical Equipment and Component Manufacturing & 1750 & 583 \\
\hline 3252 & Resin, Synthetic Rubber, and Artificial Synthetic Fibers and Filaments Ma & 1091 & 546 \\
\hline 4529 & Other General Merchandise Stores & 523 & 523 \\
\hline 3115 & Dairy Product Manufacturing & 1011 & 506 \\
\hline 1151 & Support Activities for Crop Production & 490 & 490 \\
\hline 3364 & Aerospace Product and Parts Manufacturing & 943 & 472 \\
\hline 3329 & Other Fabricated Metal Product Manufacturing & 768 & 384 \\
\hline 3116 & Animal Slaughtering and Processing & 744 & 372 \\
\hline 3149 & Other Textile Product Mills & 303 & 303 \\
\hline 3312 & Steel Product Manufacturing from Purchased Steel & 598 & 299 \\
\hline 2213 & Water, Sewage and Other Systems & 7441 & 286 \\
\hline 3118 & Bakeries and Tortilla Manufacturing & 1106 & 277 \\
\hline 1121 & Cattle Ranching and Farming & 1018 & 255 \\
\hline 3121 & Beverage Manufacturing & 2436 & 244 \\
\hline 3221 & Pulp, Paper, and Paperboard Mills & 240 & 240 \\
\hline 3271 & Clay Product and Refractory Manufacturing & 440 & 220 \\
\hline 3339 & Other General Purpose Machinery Manufacturing & 633 & 211 \\
\hline 4931 & Warehousing and Storage & 1045 & 209 \\
\hline
\end{tabular}


Table 5. Comparison by 4-Digit NAICS Category of Top Electricity Consuming Manufacturing Industries and Industrial Demand Response Potential from Audit Database Top 25 Industries by Average kW

\begin{tabular}{|c|c|c|c|}
\hline Table 1 & & Table 4 & \\
\hline 3344 & Semiconductors \& Electronics & 3211 & Sawmills and Wood Preservation \\
\hline 3261 & Plastic Products & 2123 & Nonmetallic Mineral Mining and Quarrying \\
\hline 3241 & Petroleum \& Coal Products & 3222 & Converted Paper Product Manufacturing \\
\hline 3251 & Basic Chemicals* & 5417 & Scientific Research and Development Services \\
\hline 3341 & Computers \& Peripherals & 3114 & Fruit and Vegetable Preserving and Specialty Food Manufacturing \\
\hline 3364 & Aerospace Products & 3331 & Agriculture, Construction, and Mining Machinery Manufacturing \\
\hline 3121 & Beverages & 3251 & Basic Chemical Manufacturing* \\
\hline 3273 & Cement \& Concrete & 3359 & Other Electrical Equipment and Component Manufacturing \\
\hline 3115 & Dairy Products & 3252 & Resin, Synthetic Rubber, and Artificial Synthetic Fibers \& Filaments \\
\hline 3114 & Canned \& Frozen Foods & 4529 & Other General Merchandise Stores \\
\hline 3342 & Communication Equipment & 3115 & Dairy Product Manufacturing \\
\hline 3254 & Pharmaceuticals \& Medicines & 1151 & Support Activities for Crop Production \\
\hline 3345 & Navigation \& Control Instruments & 3364 & Aerospace Product and Parts Manufacturing \\
\hline 3222 & Paper Products & 3329 & Other Fabricated Metal Product Manufacturing \\
\hline 3272 & Glass & 3116 & Animal Slaughtering and Processing \\
\hline 3279 & Other Nonmetal Minerals & 3149 & Other Textile Product Mills \\
\hline 3231 & Printing & 3312 & Steel Product Manufacturing from Purchased Steel \\
\hline 3118 & Bakeries \& Tortillas & 2213 & Water, Sewage and Other Systems \\
\hline 3323 & Structural Metals & 3118 & Bakeries and Tortilla Manufacturing \\
\hline 3116 & Meat Packing & 1121 & Cattle Ranching and Farming \\
\hline 3391 & Medical Equipment & 3121 & Beverage Manufacturing \\
\hline 3329 & Other Fabricated Metal Products & 3221 & Pulp, Paper, and Paperboard Mills \\
\hline 3328 & Coating \& Engraving & 3271 & Clay Product and Refractory Manufacturing \\
\hline 3332 & Industrial Machinery & 3339 & Other General Purpose Machinery Manufacturing \\
\hline 3119 & Other Foods & 4931 & Warehousing and Storage \\
\hline
\end{tabular}

* includes industrial gases 
Table 6. Industrial Demand Response Potential by Shift/Shed Strategy for Production; n=207

\begin{tabular}{|c|c|c|}
\hline \multicolumn{2}{|c|}{ Average of Measure Savings kW } & \multirow[b]{2}{*}{ Total } \\
\hline Strategy & Technology & \\
\hline \multirow[t]{20}{*}{ Shift Production } & Conveyors & 435 \\
\hline & All & 430 \\
\hline & Pump System & 304 \\
\hline & Electrical & 216 \\
\hline & Crushers & 200 \\
\hline & Multiple & 166 \\
\hline & Molding & 137 \\
\hline & Mixers & 136 \\
\hline & Storage & 105 \\
\hline & Motors & 83 \\
\hline & Process Heat & 79 \\
\hline & Compressed Air System & 53 \\
\hline & Grinders & 51 \\
\hline & Welding & 51 \\
\hline & Bottling & 28 \\
\hline & Battery Chargers & 25 \\
\hline & Transport System & 15 \\
\hline & Aerators & 8 \\
\hline & Fan System & 8 \\
\hline & Packing & 7 \\
\hline \multicolumn{2}{|c|}{ Shift Production Average } & 178 \\
\hline
\end{tabular}

\begin{tabular}{|l|l|r|}
\hline Average of Measure Savings kW & \\
\hline Strategy & Technology & Total \\
\hline Shed Production & All & 1038 \\
\hline & Finishing & 714 \\
\hline & Process Cooling & 386 \\
\hline & Pump System & 324 \\
\hline & Space Conditioning & 230 \\
\hline & Multiple & 95 \\
\hline & Process Heat & 77 \\
\hline & Motors & 40 \\
\hline & Molding & 24 \\
\hline & Compressed Air System & 19 \\
\hline Shed Production Average & 8 \\
\hline & Ventilation & $\mathbf{2 2 4}$ \\
\hline
\end{tabular}

Note: the designation “All” for production shift denotes a major change in production operations while the "All” designation for production shed denotes a shutdown. 
Table 7. Industrial Demand Response Potential by Shift/Shed Strategy for Supporting Systems; n=207

\begin{tabular}{|l|l|r|}
\hline Average of Measure Savings kW & \\
\hline Strategy & Technology & Total \\
\hline Shift Support & Space Conditioning & 377 \\
\hline & Motors & 167 \\
\hline & Process Cooling & 104 \\
\hline & Storage & 101 \\
\hline & Pump System & 92 \\
\hline & Refrigeration & 64 \\
\hline & Compressed Air Syster & 53 \\
\hline & Battery Chargers & 35 \\
\hline & Multiple & 17 \\
\hline & Grinders & 14 \\
\hline & Transport System & 14 \\
\hline & Welding & 9 \\
\hline & Fan System & $\mathbf{1 1 1}$ \\
\hline
\end{tabular}

\begin{tabular}{|l|l|r|}
\hline Average of Measure Savings kW & \\
\hline Strategy & Technology & Total \\
\hline Shed Support & Aerators & 539 \\
\hline & Multiple & 321 \\
\hline & Electrical & 212 \\
\hline & Compressed Air System & 165 \\
\hline & Grinders & 141 \\
\hline & Fume Hoods & 129 \\
\hline & Pump System & 113 \\
\hline & Motors & 111 \\
\hline & Reverse Osmosis & 103 \\
\hline & Storage & 99 \\
\hline & Fan System & 88 \\
\hline & Packing & 59 \\
\hline & Process Heat & 41 \\
\hline & Process Cooling & 40 \\
\hline & Space Conditioning & 38 \\
\hline & Transport System & 36 \\
\hline & Battery Chargers & 31 \\
\hline & Refrigeration & 30 \\
\hline & Lighting & 26 \\
\hline & Waste Treatment & 21 \\
\hline & Ventilation & 15 \\
\hline & Vending machine & 15 \\
\hline
\end{tabular}


Table 8. Industrial Demand Response Potential by Technology/Measure; n=207

\begin{tabular}{|c|c|c|}
\hline Measure Savings kW & & \\
\hline Technology & Sum & Ave \\
\hline Pump System & $\begin{array}{r}9326 \\
\end{array}$ & 141 \\
\hline All & 8453 & 604 \\
\hline Space Conditioning & 5449 & 73 \\
\hline Multiple & 4950 & 138 \\
\hline Compressed Air System & 3624 & 125 \\
\hline Aerators & 2163 & 433 \\
\hline Lighting & 2041 & 26 \\
\hline Process Cooling & 1598 & 89 \\
\hline Motors & 1560 & 92 \\
\hline Process Heat & 1264 & 63 \\
\hline Fan System & 984 & 76 \\
\hline Grinders & 908 & 114 \\
\hline Conveyors & 870 & 435 \\
\hline Electrical & 859 & 215 \\
\hline Storage & 804 & 101 \\
\hline Finishing & 714 & 714 \\
\hline Crushers & 600 & 200 \\
\hline Battery Chargers & 437 & 34 \\
\hline Molding & 298 & 99 \\
\hline Refrigeration & 219 & 44 \\
\hline Bottling & 138 & 28 \\
\hline Mixers & 136 & 136 \\
\hline Fume Hoods & 129 & 129 \\
\hline Reverse Osmosis & 103 & 103 \\
\hline Transport System & 101 & 25 \\
\hline Packing & 66 & 33 \\
\hline Welding & 60 & 30 \\
\hline Ventilation & 52 & 13 \\
\hline Waste Treatment & 21 & 21 \\
\hline Vending machine & 1 & 1 \\
\hline Grand Total & 47928 & 109 \\
\hline
\end{tabular}




\subsubsection{Recommendations for improved data collection}

As an outcome of collecting and conducting preliminary analyses of PG\&E audit, the DRRC Industrial Team met with PG\&E to discuss improving the quality of data collected concerning control capabilities for Auto DR in industrial facilities. At PG\&E's request, a draft template for additional information was prepared and submitted to for consideration in January 2007. A particular focus of the additional data collection is to increase knowledge of controls capability and shed/shift tolerance. See Appendix D.

\subsection{Identification and Analysis of Barriers to Implementation of Industrial Auto-DR}

Table 9 lists examples of barriers that impede the adoption of demand response (DR) in the industrial sector. It is composed of three columns: descriptions of the barriers, suggested solutions, and the entities that will need to be involved in implementing those solutions.

The first barrier shown refers simply to the lack of knowledge about DR measures that are feasible in the industrial sector. In contrast to the services sector, large energy consuming end uses in industry are considerably more heterogeneous. DR analysts are beginning to have some sense of practical and effective DR strategies for industrial applications, and sector-specific studies for California have been undertaken for the food processing and hitech/biotech sectors. However, DR opportunities in many other industries remain unknown. California's utilities have begun to require energy auditors to include recommendations for DR as well as energy efficiency, and these audits are providing a valuable new source of data for measures that are cross-cutting as well as industry-specific.

The second barrier is that incentives for facilities to participate in DR events are simply not attractive enough to justify much effort, whether staff time or other expenses dedicated to enabling DR. This is particularly true in the industrial sector, where many potential DR measures could result in either production losses or costs increases related to shifting production. The 2005 program evaluation indicated that at current incentive levels the economic DR potential from non-participants is only 280 MW (Quantum Consulting, 2006). The utilities and the California Public Utilities Commission (CPUC) will probably need to redesign the tariff structure of DR programs in order to adequately reward facilities that achieve significant reductions.

The operational barrier describes the fact that industrial customers are sometimes not able to implement measures within the short lead time given by the current notification schedule in the utilities' DR programs. Unlike HVAC or lighting measures, DR strategies with large potential in the industrial sector may require some reorganization of production or shipping schedules. A notification system that gives manufacturers a longer lead time might facilitate certain measures that would otherwise go untapped. 
Table 9. Barriers Analysis of Industrial Demand Response

\begin{tabular}{|c|c|c|}
\hline Barrier & Solution & Implementer \\
\hline $\begin{array}{l}\text { Poor Understanding of Technical } \\
\text { Potential of Measures in Industry }\end{array}$ & $\begin{array}{l}\text { Subsectoral assessment of } \\
\text { DR potential by }\end{array}$ & PIER, DRRC \\
\hline $\begin{array}{l}\text { Economic: Insufficient } \\
\text { DR Incentives, Revenue }\end{array}$ & Tariff reform & $\begin{array}{l}\text { Utilities, } \\
\text { CPUC }\end{array}$ \\
\hline $\begin{array}{l}\text { Operational: Insufficient Time to Adjust } \\
\text { Production or Implement Measures }\end{array}$ & $\begin{array}{l}\text { Earlier notification, targeted Auto- } \\
\text { DR possible with technical } \\
\text { knowledge }\end{array}$ & $\begin{array}{l}\text { Utilities, } \\
\text { CPUC }\end{array}$ \\
\hline Missed Notification & $\begin{array}{l}\text { Improved notification systems, } \\
\text { validation, send notifications to } \\
\text { multinle contacts. Auto-DR }\end{array}$ & $\begin{array}{l}\text { Utilities, PIER, } \\
\text { DRRC }\end{array}$ \\
\hline $\begin{array}{l}\text { Technical Knowledge at } \\
\text { Facilities }\end{array}$ & $\begin{array}{l}\text { Expand DR audits, publication of an } \\
\text { Industrial DR Guide, DR training }\end{array}$ & $\begin{array}{l}\text { Utilities, PIER, } \\
\text { DRRC, control }\end{array}$ \\
\hline Cost-Benefit Evaluation & $\begin{array}{l}\text { Research on costs of DR measures } \\
\text { (productivity)and DR savings valuation }\end{array}$ & $\begin{array}{l}\text { PIER, DRRC, EPRI, } \\
\text { trade associations }\end{array}$ \\
\hline $\begin{array}{l}\text { Facility Staff Time Constraints and } \\
\text { Repeatability }\end{array}$ & Auto-DR & $\begin{array}{l}\text { Utilities, PIER, } \\
\text { DRRC, control }\end{array}$ \\
\hline
\end{tabular}


Missed DR event notifications were a common problem that surfaced for several sites among the submetering case studies in the 2005 Evaluation (Quantum Consulting, 2006). Some facility managers reported that they were often busy or unavailable when notifications were sent. At one submetered site, the 2005 events were missed because notifications were being sent to a staff member who had departed. Greater use of AutoDR would help overcome this barrier by obviating the need to notify facility staff. Notification systems that automatically alert two or three staff members per site might also help to ensure that events are not missed for these reasons.

The technical knowledge barrier differs from the technical potential barrier in that technical potential concerns the macro policy level while technical knowledge refers to facility-level implementation. Once certain industries and processes have been targeted on the basis of their technical potential, some training for facility managers and possibly controls vendors will still be required to help facility managers understand how to respond to events and integrate DR into their control systems. Technical knowledge about executing DR measures can be enhanced by expanding the number of DR audits, creating DR guides for the most promising measures in targeted sectors, and initiating workshops to provide DR training on successful strategies and the use of various energy management systems to implement measures.

A cost-benefit barrier has been encountered in evaluations of DR programs in that facility managers rarely have a good grasp of the financial implications of participating in DR measures. This relates to the first barrier, because little analysis has been done of the costs of enabling or executing DR measures on industrial processes. Even on the benefit side, facility managers in California have several DR and reliability tariffs to choose from. Few facility managers have been willing to spend the time analyzing these tariffs against their estimated DR potential to determine what benefits will actually accrue to their plants. A beta version of a DR valuation tool has been developed to help users evaluate the benefits of different programs, but it has not yet been widely released. (EPRI, 2005) Finalization and dissemination of the tool might be helpful for facility managers to determine which, if any, DR program makes sense for their companies.

Another finding of the 2005 Evaluation was that staff time constraints were cited as one reason that several facilities did not participate in DR events. Even when facility managers receive notifications, they may be too busy to execute the manual DR strategy. This may be exacerbated by the fact that current incentives may be too low for facility managers to prioritize DR. Automated DR overcomes this barrier by avoiding the need for human action to realize the DR reductions. However, automated DR systems in the industrial sector face their own set of obstacles. They are currently very rare and further technological development, standardization of protocols, and staff training will be required before automated DR becomes widespread in the industrial sector.

This analysis of barriers to industrial DR reveals that seven key obstacles impede greater adoption of DR in industry. The first obstacle necessitates ongoing basic research to identify a portfolio of DR measures that industries can execute with little or no impact on production. The economic, operational, and notification barriers require intervention 
from the utilities and the CPUC in order to redesign certain aspects of the DR programs currently offered. The last three barriers all concern the capacity of facility managers to understand DR strategies, evaluate the costs and benefits of DR programs, and execute measures when events are called. Better tools, technical assistance, and development of automated DR technologies would contribute to overcoming these barriers.

\subsection{Collaboration on Recruitment and Implementation}

From April through September 2007, the DRRC Industrial Team coordinated closely with Global Energy Partners (GEP) in the identification and recruitment of industrial sites for Auto-DR. This coordination included weekly meetings to discuss prospects and to plan joint site visits as needed. During this period, Team members participated in a number of industry meetings, especially at the invitation of the Silicon Valley Leadership Group (SVLG). Several tools were developed by the Team to assist in the recruitment process, including a site questionnaire and two fact sheets on Auto-DR for data centers and industry in general.

\subsubsection{Site Questionnaire}

The Site Questionnaire was developed by the DRRC Industrial Team in response to a need to have a more structured method for initial data collection from potential Auto-DR candidates. The final product includes useful input from EPRI and is meant to be selfdirected. The questionnaire received limited use during the 2007 season because it was completed in July, but is anticipated to provide a better structure for recruitment during the 2008 season. See Appendix E.

\subsubsection{Informational Pieces}

Two fact sheets were developed by the DRRC Industrial Team for the purpose of communicating the purpose, benefits, and possible strategies for Auto-DR in data centers and in industry more generally. Both fact sheets were used during the 2007 season for this purpose and will be revisited prior to the 2008 season to determine whether additional refinement is needed. See Appendix F for copies of the fact sheets.

\subsubsection{Implementation}

The implementation process to recruit industrial customers for AutoDR involved identifying and validating the load shed/shift opportunity and estimating the plant technology upgrade. The DRRC Industrial Team coordinated with GEP on a process that included completing a customer participation agreement, scheduling a kick-off meeting, assigning a technical coordinator to implement the technology upgrade, and performing a test to validate the opportunity. The DRRC Industrial Team participated in a number of implementation activities that included weekly conference calls, networking and referrals, developing and maintaining a prospect list, site visits, research and technical review, and training. The weekly conference calls were used to discuss and share information concerning potential industrial sites, the recruitment process, and to refine target sector strategies as experience was gained. In addition to GEP's recruitment efforts, leads were generated through the Team's outreach and coordination to industrial 
associations, consultants, and others. Members of the Team also participated in and/or hosted PG\&E InterAct and Auto-DBP technical coordinator training.

\subsubsection{Outcomes}

The principle purpose for involvement of the DRRC Industrial Team in the 2007 recruitment activity was to assist GEP in meeting the $15 \mathrm{MW}$ Auto-DR reduction target for PG\&E by engaging industry. Another important purpose was to build on the Team's existing knowledge of what works for Auto-DR in industrial markets.

As the result of this work the DRRC Industrial Team assisted GEP in exceeding their 15 MW goal for Auto-DR through the participation of two industrial sites. The Team worked with GEP to assist them in securing agreements with an industrial gas firm to commit $10 \mathrm{MW}$ to Auto-DR. This production process shed is applicable to other industrial gas facilities within the same company and has generated interest from other industrial gas companies for 2008. A more complete description of this site is included in Appendix G.

Figure 5 shows the electric load shed that occurred on August 30, 2007 when the PG\&E automated demand-bidding program was tested. The majority of this load shed came from a large industrial site. The load did not return until the late morning of August $31^{\text {st }}$, 2007.

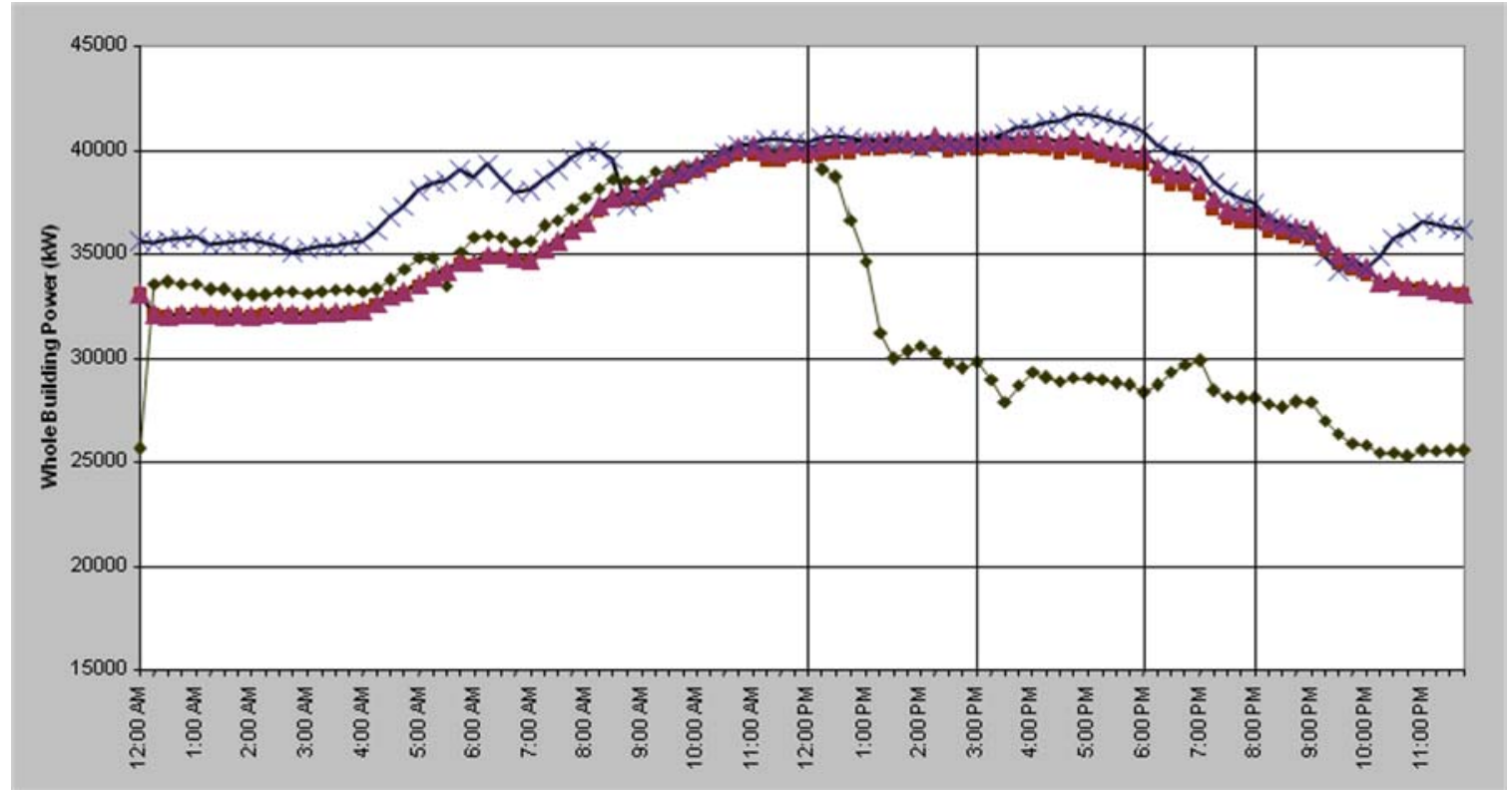

Figure 5. Load Shed Test August 30, 2007

In addition, the DRRC Industrial Team directly recruited a recycling facility for Auto-DR that resulted in a signed agreement for a $5 \mathrm{MW}$ shift. This type of production shift (hammer mill) could be applied to many other industrial facilities that use similar equipment, e.g., such as crushing operations in the mining industry. 
Table 10 provides an overview of impact from the participation of specific industrial sectors as a percentage of PG\&E's total Auto-DR demand reduction in 2007. A relatively small percentage of industrial facilities account for $62.5 \%$ of the overall demand reduction.

Table 10. 2007 PG\&E Auto-DR Participation Profile (industry as a \% the total)

\begin{tabular}{|l|r|r|}
\hline \multicolumn{1}{|c|}{ Business Type } & \% Program Participants & \% kW Demand Reduction \\
\hline High Tech & 30.2 & 9.9 \\
\hline Biotechnology & 4.8 & 1.1 \\
\hline Industrial Process & 4.8 & 62.5 \\
\hline Data Center & 1.6 & 3.1 \\
\hline
\end{tabular}

Source: GEP July 2007

It is important to note that although these production sheds and shifts are large and significant, further research into the feasibility of smaller sheds and shifts that do not disrupt production is needed if Auto-DR is to become more widespread in California industry. Most companies simply will not have the ability to affect production to this degree.

The DRRC Industrial Team also focused on data center Auto-DR strategies as potential research demonstrations. Two demonstration sites are under development. The significance of potential in data centers can be summarized as follows:

- Unlike much of the industrial sector, the electricity use of data centers is growing rapidly;

- $\quad$ Servers are grossly underloaded - 10-15\% utilization rate is typical, so higher utilization rates would allow servers to be temporarily shut down.

Increased loading of servers can be accomplished through:

- Server consolidation software to increase the loading to $40 \%$ or more;

- Virtualization - segregating several tasks within one server;

- Task Prioritization - shutting down low-priority task servers.

The DRRC Team is in discussion with two software vendors on full integration of AutoDR into their products.

Table 11 shows the $27 \mathrm{MW}$ (18.4 MW plus 8.6 MW) of Auto-DR recruited into the PG\&E, SCE, and SDG\&E Auto-DR programs. There were no industrial participants in 2006. 50\% of the $27 \mathrm{MW}$ are from industrial facilities. As discussed above, the demand reduction as a percent of the total facility load is quite large. The average reduction for three industrial facilities that are currently configured for Auto-DR is $46 \%$ with even larger demand reductions of $66 \%$ for the 8 sites in process. The industrial facilities are reducing their peak demand in a larger fraction than the commercial buildings. Further research is needed to understand how these large demand reductions perform over time within the demand bid and critical peak pricing programs in which they are configured to participate. 
Table 11. Auto-DR Program Goals and Results

\begin{tabular}{|l|l|l|l|}
\hline & 2006 & $\begin{array}{l}2007 \\
\text { Production }\end{array}$ & $\begin{array}{l}2007 \\
\text { In-Process }\end{array}$ \\
\hline $\begin{array}{r}\text { 1. Accelerate Implementation } \\
\text { - Commercial participants }\end{array}$ & 13 & 125 & $\begin{array}{l}16 \\
8 \\
\text { - Industrial participants }\end{array}$ \\
- Peak Load Reduction & $1.1 \mathrm{MW}$ & $18.4 \mathrm{MW}$ & $8.6 \mathrm{MW}$ \\
\hline $\begin{array}{l}\text { 3. Expand the role of Technical } \\
\text { Providers }\end{array}$ & none & 8 industry participants \\
\hline $\begin{array}{l}\text { 4. Improve DR performance } \\
\text { - Commercial }\end{array}$ & $13.0 \%$ & $19.9 \%$ & $12.3 \%$ \\
- Industrial & -- & $45.5 \%$ & $65.9 \%$ \\
- Aggregate All Participants & -- & $30.7 \%$ & $37.4 \%$ \\
\hline
\end{tabular}

\subsection{Scoping Studies}

Scoping studies were undertaken in 2007 to examine Auto-DR potential in depth in two sectors: food processing and the semiconductor industry.

The food processing study examined DR potential (not limited to Auto-DR), existing levels of participation, experiences, information sources, and use of tools and technologies. The primary means of data gathering was a survey administered to food processing companies. The survey results suggest that opportunities exist to both reduce and shift essential demand (i.e., manufacturing-related demand) and non-essential demand (e.g., office buildings, warehousing, etc.). The primary reasons cited by respondents for enrolling and not participating in DR were plant production schedule constraints, lack of program cost-effectiveness, other priorities, and lack of resources. Of those participating in DR, the primary reasons given were corporate environmental citizenship and economics ${ }^{9}$

The second scoping study, still in development, is designed to produce an operations guide for automating demand response in the semiconductor industry. This guide will be centered around a few key strategies such as process storage for ultra-pure water and cleanroom air velocity reduction.

\footnotetext{
${ }^{9}$ Lewis, Glen. Unpublished final draft. Strategies to Increase California Food Processing Industry Demand Response Participation, prepared for the DRRC and the California Energy Commission, PIER.
} 


\subsection{Submetering}

In 2006 another industrial site was added while two industrial sites stopped participation. Thus in 2007, there were five industrial sites participating in submetering and various DR programs. One of the sites participated in demand-bid pricing (DBP) while the other four were on critical peak pricing (CPP), with one of those on Auto-CPP.

In the analysis of the data from the submetered sites, the reader should be aware that the conclusions reached are based on data from three to five readings of various pieces of equipment or groups of equipment, which may not represent the total energy usage at the site. Thus the conclusions below may not be representative of the energy usage and corresponding DR level of participation at the whole site.

The lone site that participated in DBP had 22 events called by its utility. Of those 22 events, there is only clear evidence that this site participated in six events. On the remaining non-participatory event days, the site often used higher total energy. The days in which participation was clearly visible, the reduction was about $20 \%$ as compared to previous days.

The remainder of the sites participated in CPP. The one site on Auto-CPP is discussed below. Of the three "manual" CPP sites, two sites show no indication of reducing energy use during events. One site may have actually had higher energy use during some event days.

The single site on "manual” CPP shows decreases in energy use in a refrigeration unit on event days, from $70 \mathrm{~kW}$ to $10 \mathrm{~kW}$, but the main building shows an energy increase, from $140 \mathrm{~kW}$ to $180 \mathrm{~kW}$. The sum is an energy decrease but not as high as if the refrigeration decrease was not offset by an increase in energy usage in the main building. This one site needs more data analysis to calculate the overall energy savings during event days.

Of the remaining sites that were on CPP, the one site on Auto-CPP showed consistent participation on event days. There was one piece of equipment that used no energy during CPP events during the time period 15:00 to 18:00. The equipment was consistently used immediately before and after the period 15:00 to 18:00. Since the site is on Auto-CPP, this consistent participation is not surprising. But what is surprising is that for about half of the event days, this piece of equipment was off during the time period 15:00 to 18:00 several days before the event. It appears that the Auto-CPP strategy for this piece of equipment was also occasionally used as an energy efficiency measure. 
Table 12. Industrial Participants in Sub-Metering Study

\begin{tabular}{|c|c|c|c|c|c|c|}
\hline Site & Industry & Program & $\begin{array}{l}\text { Participation } \\
2004\end{array}$ & $\begin{array}{l}\text { Participation } \\
2005\end{array}$ & $\begin{array}{l}\text { Participation } \\
2006\end{array}$ & $\begin{array}{l}\text { Participation } \\
2007\end{array}$ \\
\hline 1 & Chem Repackaging & CPP & Yes & Yes & No & No \\
\hline 2 & $\begin{array}{l}\text { Fruit Proc \& Cold } \\
\text { Storage }\end{array}$ & СРР & Yes & Yes & Frequent & Frequent \\
\hline 3 & $\begin{array}{l}\text { Baking w/ Frzn } \\
\text { Storage }\end{array}$ & СРР & Yes & Yes & Little to none & $\begin{array}{l}\text { Little to } \\
\text { none }\end{array}$ \\
\hline 4 & $\begin{array}{l}\text { Fruit Proc \& Cold } \\
\text { Storage }\end{array}$ & DBP & Yes & Yes & Occasional & Occasional \\
\hline 10 & Glass & DBP & No & No & Dropped Out & \\
\hline 12 & $\begin{array}{l}\text { Baking w/ Frzn } \\
\text { Storage }\end{array}$ & DBP & No & No & Dropped Out & \\
\hline 13 & Baking & AutoCPP & Not enrolled & Not enrolled & Not enrolled & $\begin{array}{l}\text { All June \& } \\
\text { July dates }\end{array}$ \\
\hline
\end{tabular}

Table 12 provides summary information on the six industrial sites. Of the six, two did not participate in any DR events and dropped enrollment by 2006. Three of the four sites that did participate in both years are food-processing plants whose principal DR strategy was to adjust settings of their cold storage units. Site 1 is the only non-food processing plant to participate. This was also the only site to execute a strategy involving multiple measures. An additional site was added to the sub-metering study in 2006, but it was instrumented too late in the summer to record any events. This facility is a large baking operation that is relying on one DR measure to respond to events.

An examination of the sub-metering participants to date reveals that while many valuable lessons have been learned from the sub-metering study (Murtishaw, 2006), its usefulness suffers from three large shortcomings that any future sub-metering should seek to overcome. First, one-third of the selected sites never participated at all. Selected sites need to be carefully vetted to determine that they are very likely to participate in DR events. Second, the sample does not include a broad enough range of California industries. Only one non-food processing facility has been studied to date, and while it is involved in final production of chemicals, it is not an energy-intensive primary producer. If possible, participants should be recruited from among the top nine electricityconsuming manufacturing sectors (see Table 1) to determine strategies that can be repeated by other large consumers of electricity. Third, facilities need to be recruited that can offer a more complex suite of DR measures since one of the principal advantages of sub-metering is to determine which end uses contribute most to the observed curtailments. This is related to the lack of sectoral diversity. Other industries may provide opportunities to quantify DR savings from measures such as pumping, compressed air, grinding, mixing, or conveyance. 


\subsection{Key Findings}

When this research was initiated in October 2006, the actual opportunities for implementing industrial DR in California, especially price-responsive and Auto-DR were unclear. While many industrial facilities have participated in reliability and "day ahead" notification programs (1857 MW and $1044 \mathrm{MW}$, respectively in 2005) ${ }^{10}$, a program goal is to "harden' the industrial response so that it becomes a more reliable resource for managing the cost and supply of electricity. The DRRC had successfully implemented and began commercialization of Auto-DR for commercial buildings, but the industrial sector presented unique challenges - technical, operational, and managerial. While previous analyses (EPRI 2005, KEMA 2007) seem to indicate substantial potential, realizing this potential requires developing a portfolio of approaches, DR strategies, and techniques that both simplify participation and offer clear business value.

One year into this field of study, the DRRC Industrial Team has collected sufficient survey and empirical field data to conclude that there appears to be great potential for Auto-DR in industrial facilities. This finding needs to be qualified. Further research is needed to understand 1) organizational decision-making processes as they impact DR participation and 2) the role of existing and emerging industrial controls in contributing to the ability to readily participate in Auto-DR, 3) end-use process control capabilities to support reduced service and process control levels during DR events.

Assumption\#1: Industry will not participate in DR programs that pose a threat to operations, such as shift or shed strategies that affect production, unless there is a clear and immediate threat to the reliability of the electric supply system.

Key Finding: Some industrial facilities will shift or shed process load based on financial incentives, not just to protect reliability.

- In certain niche markets, such as industrial gases, electricity is a large proportion of operating costs. As a result, demand management is an integral part of the operating culture with sophisticated controls. For these markets, Auto-DR offers a cost-management opportunity that is integrated into the production schedule

- Shifting a batch process, such as a hammer mill, may be acceptable as an AutoDR strategy even if it is not be something done on a daily basis.

Assumption \#2: Industrial demand response competes with industrial energy efficiency for scarce industrial plant resources.

Key Finding: Auto-DR is compatible with energy efficiency and load management in industrial facilities.

- Plants who express interest in Auto-DR are typically already engaged in both energy efficiency and demand management improvements. Auto-DR is another

${ }^{10}$ Quantum 2006 
cost-reduction tool, not a replacement for energy efficiency and demand management ${ }^{11}$.

Assumption \#3: Many Industrial plants have the control system capabilities necessary to participate in Auto-DR.

Key Finding: Many industries have limited controls capabilities, especially for supporting or non-core systems that may be suited for Auto-DR ${ }^{12}$. There is an emerging market for demand management and system-level network controls that could allow Auto-DR to be integrated. Discrete controls offer less Auto-DR capability.

Our research identified opportunities for demonstrations or case studies in several areas:

- Adaptation of existing demand management software for Auto-DR applications;

- Minor modification to make network controls for supporting systems DRenabled;

- Modification of Auto-DR software designed for energy efficiency and load management in data centers;

- Opportunities to "think beyond the plant” by bundling similar Auto-DR shed strategies into a single controls network so that sheds could be "tuned" to actual needs within the scope of individual participation agreements.

Assumption \#4: The financial benefits presented by Auto-DR may not be sufficiently attractive for most industries to be worthwhile.

Key Finding: The current portfolio of DR programs is confusing, but the availability of financial incentives and technical assistance can make participation attractive.

Industrial facilities are not concerned with DR, since their focus is on core production. The current DR programs and tariffs are so complex that they create challenges. Unless the incentives are substantial, most industries are not willing to study the potential benefits. A simpler approach is needed.

However, if the utility tariffs move toward dynamic pricing, Auto-DR may provide an infrastructure for facility price response for some facilities. ${ }^{13}$

\footnotetext{
${ }^{11}$ Initial findings from the 2009-2020 Statewide Energy Efficiency Plan stakeholder input process seem to support this perspective. See http://www.californiaenergyefficiency.com/industrial.shtml for workshop and webcast notes Nov-Dec 2007.

${ }^{12}$ For instance, in an unpublished paper, Drilling Down Below the Revenue Meter: Understanding Customer Demand Response Strategies through Sub-metering, John Bidwell of Quantum Consulting describes how "all of the six industrial sites in the sub-metering sample utilized manual controls to activate and control load reductions”.

${ }^{13}$ Note: for some sectors, such as fruit and vegetable processing, peak production is coincident with peak statewide electricity use. Substantial concerns have been expressed by these industries concerning their structural inability to respond to dynamic pricing during the summer months. Suggestions include "teaming" with other sectors that have this potential to build greater reliability into the grid without adverse consequences to their operations.
} 
Assumption \#5: It should be possible to identify potentially attractive DR shift or shed strategies for specific industrial sectors.

Key Finding: It is possible to define DR shed/shift strategies for specific industries.. We can develop preliminary "short lists" for promising sectors to further evaluate their feasibility.

Although the sample size was limited (207 records) and is based on recommended rather than implemented strategies, nine 4-digit NAICS categories were identified as in the top25 for both large users of manufacturing electricity (Table 1) and DR potential by average $\mathrm{kW}$ from the utility integrated audits (Table 4). These categories include:

- Converted Paper Product manufacturing

- Fruit and Vegetable Preserving and Specialty Food Manufacturing

- Basic chemical manufacturing, especially industrial gases

- Dairy Product manufacturing

- Aerospace Product and Parts Manufacturing

- Other Fabricated Metal Product Manufacturing

- Animal Slaughtering and Processing

- Bakeries and Tortilla Manufacturing

- Beverage Manufacturing

Of these, the industrial gas sector appears to be ready for implementation. Anecdotal evidence from industrial end users indicates that demand response opportunities may be found in other industrial sectors. The key research question is "to what extent can and will these facilities accept automation of DR?” The nine sectors listed above were compared against recommendations in other related reports ${ }^{14}$ : We recommend an initial "short list" of five industrial sectors recommended for further study based on knowledge of these sectors:

- Cold storage

- Data centers and test labs for high tech industries

- Water/wastewater

- Aerospace products

- Beverages, including breweries and wineries

As previously noted in Section 1.2, refrigerated warehouses are a category worthy of further study. These facilities are attractive due to the relative homogeneity of the technology and the relative ease of implementing DR, as demonstrated in the submetering studies in the 2005 Evaluation Report (Quantum Consulting 2006).

\footnotetext{
14 These reports are: Evaluation of 2005 Statewide Large Nonresidential Day-Ahead and Reliability Demand Response Programs by Quantum Consulting (2006) and Demand Response Analysis and Tool Development for Industrial, Agricultural and Water (IAW) Energy Users by EPRI for the California Energy Commission (2005).
} 
Data centers are also an area of significant promise, both due to underutilization of computing assets and the high level of comfort with automated controls. Reliability has an extremely high value for enterprise type data centers, but greater opportunities for Auto-DR can be found in the large number of data centers that are laboratories for testing applications. Unlike many other industries, data centers are an area of great growth in electrical usage, with electricity use projected to rise nationally from an estimated 7 gigawatts (GW) currently to $12 \mathrm{GW}$ by 2011, based on a business as usual scenario. ${ }^{15}$ In addition, the industry as a whole is very motivated toward developing a "green" image. Both of these factors contribute to a significant potential for Auto-DR in data centers.

As a comparison, the EPRI study identified cement, electronics, industrial gases, and water agencies as "good" candidates for demand response and metal castings, food processing, petroleum refining, and pulp and paper as "fair" candidates. The Quantum evaluation of 2005 day ahead and reliability demand response programs identifies three clusters of industries as the key participants:

- petroleum, plastic, rubber and chemicals

- mining, metals, stone, glass, and concrete

- electronic, machinery, and fabricated metals.

Other areas of interest include: paper products, plastics, dairy products (cheese), bakeries, cement, and electronics manufacturing.

While there is a wide range of potential shift and shed strategies requiring further study, those most frequently identified in the utility integrated audits are:

- For production shifts, conveyors, all systems, pump systems, and electrical;

- For production sheds, all systems (stop production), finishing, process cooling and pump systems;

- For supporting system load shifts, space conditioning, motors, process cooling, and storage; and

- For supporting system load sheds, aerators, multiple systems, electrical, and compressed air.

\footnotetext{
${ }^{15}$ U.S. Environmental Protection Agenct ENERGY STAR Program. August 2007. Report to Congress on Server and Data Center Energy Efficiency, Public Law 109-431
} 


\subsection{Promising Areas for Future Research}

Referencing back to Section 1.2.1, the Key Research Questions are:

1. Where is the potential to shed or shift electricity use in industry?

- Which sectors have the greatest potential to shed or shift during peak periods?

- Have these sectors been active in reliability programs or identified in audits?

2. What is the functional capability of specific industries to implement Auto-DR?

- What are the control gaps and the associated cost of implementing Auto-DR?

- Of sectors identified as having Auto-DR potential, which offer the most costeffective implementation opportunities?

3. What are the market trends in industrial controls that support Auto-DR?

- Do advances in control technologies make specific sectors or systems attractive candidates for Auto-DR?

- What are the technology gaps that might benefit from public R\&D?

4. What are the market and operational barriers to the implementation of reliability and price-responsive industrial DR?

- Do industrial energy managers understand economic and societal benefits of DR

- What roles do price and incentives have in the decision making process?

- What are the areas tension between DR and industrial plant schedules?

5. What is the role of industrial Auto-DR in the state's goal to provide reliable and climate-friendly electricity at a reasonable cost to CA consumers?

- Is there “migration potential” for DR strategies in promoting industrial load management and energy efficiency in industrial facilities?

The first year of research has identified a number of opportunities for additional study that would build on the emerging body of knowledge in this area. Future work of the Industrial Team should consider the following:

1. Form a Technical Advisory comprised of representatives from industry and the suppliers and consultants that serve them to guide the work of the DRRC Industrial Team

2. Examine the issue of controls capability and compatibility

o Develop a survey of existing industrial control capabilities, to be administered via the web in cooperation with key industrial associations (California Manufacturers and Technology Association, California League of Food Processors, Silicon Valley Leadership Group, etc)

o Draft a discussion piece describing key control issues for successful implementation of Auto-DR 
o Host a workshop of control experts from the demand response, demand management, and industrial system control communities to critique the discussion piece and recommend a path forward

o $\quad$ Draft a white paper based on outcomes from the critique

o Host 2-3 workshops with industrial associations to share the outcomes of the controls workshop and further refine the white paper

o Publish paper on the technical capacity for Auto-DR in CA industry

3. Conduct additional research and develop DR Strategy Guides (initially Refrigerated Warehouses and Data Centers)

4. Conduct further research on industrial energy use patterns in California, with the goal of identifying specific sheds and shifts in sectors previously identified as showing potential

5. Investigate opportunities for demonstrations of DR-enabled controls as an integrated feature original equipment manufacturers

o $\quad$ Compressed air and pumping system networked controls

o Virtualization/prioritization software for data centers

Although not specifically targeted, some of this research can also be used to enhance the current understanding of industrial management decision-making as it pertains to DR. Finally, a major area for additional research currently outside of the DRRC scope concerns improving program and tariff design to better promote Auto-DR in industry.

For the second year of research, the DRRC proposes to work with a Technical Advisory Group comprised of representatives from industry and the suppliers and consultants that work with them. This research will be directed toward key research questions outlined above to assist the California Energy Commission (CEC), the California Public Utilities Commission (CPUC), and the investor-owned utilities in more effectively targeting their Auto-DR efforts. 


\subsection{Conclusion}

The DRRC Industrial Team research has shown that industrial facilities can be good candidates for demand response and that, under the right conditions, some types of industrial facilities will shift or shed process load based on financial incentives, not just to protect reliability. The DR industrial project also facilitated the initial implementation of the Auto-DR technology in several large industrial facilities. This effort was coordinated with California utilities. While details of the automation controls linkage is proprietary, these installations have shown the CLIR box can be installed with many industrial control infrastructures.

Participation in the 2007 recruitment and implementation also led to the development of several tools (Site Questionnaire, Informational Pieces) that should assist recruitment efforts in future years. The process of developing these tools also enhanced the Team's understanding of the information requirements, potential benefits and barriers for participating in Auto-DR.

In addition, the research required to develop the draft road map and the initial analysis of electricity use in California manufacturing industry was a useful starting point in developing an understanding of industrial DR potential. The analyses of utility demand response audit data built on those efforts. These data have proven useful in beginning to narrow the scope of future study on the types of sheds or shifts that can be effectively automated in specific plant types. From the database, the potential sheds or shifts identified include both production and supporting systems: conveyors, pump systems, process cooling, electrical systems, motors, aerators, and compressed air. These data provide a foundation for further data collection and study that will assist California in targeting specific demand response programs to the most receptive industries. The longterm goal is to develop checklists of potential Auto-DR strategies targeted to specific industries to assist them in working with their utilities to develop an implementation plan. 


\subsection{References}

Braithwait, Steven and David Armstrong. 2004. Potential Impact of Real-Time Pricing in California. Christensen Associates.

California Energy Commission. 2002. An Action Plan to Develop More Demand Response in California’s Electricity Markets. Sacramento, CA. P400-020016F

EPRI (Electric Power Research Institute), 2005. Demand Response Analysis and Tool Development for Industrial, Agricultural and Water (IAW) Energy Users. Sacramento, CA: California Energy Commission.

Ganji, Ahmad. 2007. Lessons Learned from Energy and Demand Response Audit Projects in California, presentation at ISA NorCal Tech 2007 Conference, Vallejo, CA

Goldman, C. and N. Hopper, O. Sezgen, M. Moezzi, R.Bharvirkar, B.Neenan, D.Pratt, P. Cappers, and R.Boisvert. 2004. Does Real-Time Pricing Deliver Demand Response? A Case Study of Niagara Mohawk’s Large Customer RTP Tariff. LBNL-54974

Kathan, David. 2006. FERC Staff Report on Demand Response and Advanced Metering. Presentation to NYISO http://www.ferc.gove/legal/staff-reports/demand-response.pdf

KEMA, with assistance from LBNL and Quantum Consulting. May 2006. California Industrial Existing Construction Energy Efficiency Potential Study Final Report to Pacific Gas and Electric Company.. CALMAC Study ID: PGE2052.01.

Kiliccote, S., M.A. Piette, D.S. Watson, G. Hughes. 2006. Dynamic Controls for Energy Efficiency and Demand Response: Framework Concepts and a New Construction Case Study in New York, Proceedings, 2006 ACEEE Summer Study on Energy Efficiency in Buildings. LBNL-60615.

Kiliccote, S., M.A. Piette, D. Hansen. 2006. Advanced Controls and Communications for Demand Response and Energy Efficiency in Commercial Buildings, Second Carnegie Mellon Conference in Electric Power Systems: Monitoring, Sensing, Software and Its Valuation for the Changing Electric Power Industry. DRRC Report. LBNL-59337

Motegi, N., M.A. Piette, D.S. Watson, S. Kiliccote, P. Xu. 2007. Introduction to Commercial Building Control Strategies and Techniques for Demand Response, report for the California Energy Commission, PIER. LBNL-59975

Murtishaw, S, 2006. Summary of Key Lessons from WG2 Submetering Summary, unpublished memo by Scott Murtishaw, Lawrence Berkeley National Laboratory

Piette, M.A., D. Watson, N. Motegi, S. Kiliccote. 2007. Automated Critical Peak Pricing Field Tests: 2006 Pilot Program Description and Results. LBNL-62218. 
Quantum Consulting, 2006. Evaluation of 2005 Statewide Large Nonresidential DayAhead and Reliability Demand Response Programs: Final Report.

http://www.calmac.org/publications/2006-04-28_WG2_2005_FINAL_REPORT.pdf

Wikler, Greg, Joe Priyanonda, Mary Ann Piette, Sila Kilicote, Grish Ghatikar, June Han, and Dan Hennage. 2007. Southern California Edison Auto-DR Pilot Program Assessment Report, Los Angeles, CA Southern California Edison.

York, Dan and Martin Kushler. 2005. Exploring the Relationship Between Demand Response and Energy Efficiency: A Review of Experience and Discussion of Key Issues. American Council for an Energy Efficient Economy, Washington, DC Report \# U052. 


\section{Appendices}


Appendix A: Industrial Demand Response Strategic Roadmap

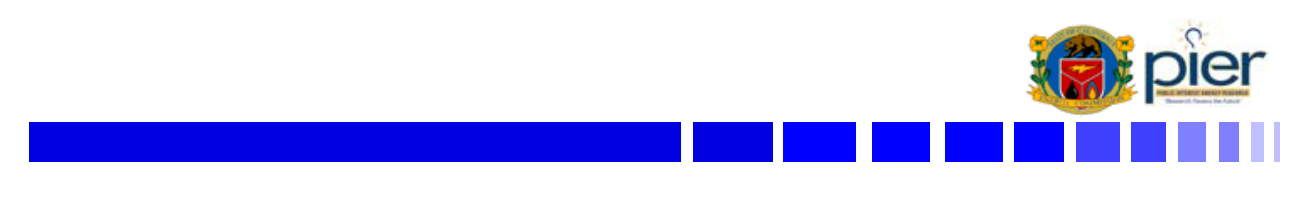

\title{
Industrial Demand Response Strategic Roadmap
}

\author{
November 15, 2006 (draft) \\ Public Interest Energy Research Program \\ California Energy Commission
}


What are the goals of PIER's industrial demand response research over the next three years (2007-2009)?

1. To conduct research to support the development of a firm demand response resource from California industry for critical peak periods

2. To increase the participation of California industry end users in all types of electricity demand response

3. To investigate options for linking industrial demand response (DR) with energy efficiency (EE) to most effectively use electricity and natural gas in California industry 
What do we need to know to develop a firm demand response from CA industries?

- What types and size of electrical loads are CA industries most likely to be able to shed or shift (technical capability)?

- Which of these electrical loads are CA industries most likely to be willing to shed or shift and by how much (economic interest, amount of DR)?

- Which loads could CA industries subject to an automated demand response (AutoDR)? (technical and economic)

- How can demand response programs, especially AutoDR, be structured to offer industry a clear incentive to participate?

- Commitment lead time, extent of commitment, event notification

- Firm DR commitment options

- Enabling technologies

- Financial incentives

\section{Existing Resources}

- CA industrial energy use by sector

- Substantial data on a wide range of sectors

- Resources include:

- California Energy Balance database with electricity usage by over 35 industrial sectors

- Estimates of facility-specific electricity consumption for select large energy users

- DRRC Demand Response database

- Industrial load types and processes by sector

- Information varies from limited to fairly detailed, depending on sector

- Integration of existing research would be very helpful

- Resources include:

- Reports such as CEC's Demand Response Analysis and Tool Development for Industrial. Agricultural, and Water (IAW) Energy Users

- USDOE Energy Footprints

- USEPA Energy Guides for Industry

- Data on peak loads disaggregated at the two-digit SIC level by eight different process types

- LBNL reports on trends and usage patterns of electricity use in CA and industryspecific analyses of energy consumption by several large industries 
- Industrial loads that industry is likely to agree to shed or shift

- CA utility programs have experience with industry participation in interruptible demand response, critical peak pricing, demand bidding

- Targeted research is being conducted for a few sectors

- Scoping studies now underway for the food processing, high tech, and biotech industries

- Results of submetering case studies

- Additional scoping and validation research is needed

- To target industrial systems and processes found in many plants and/or sectors

- To identify which systems and processes have the technical potential to be AutoDR candidates

- To identify the conditions under which a facility with these systems or processes would consider participating in AutoDR

Strategic Roadmap

Goal: increase \& firm up industrial participation in DR

\begin{tabular}{|c|c|c|c|c|}
\hline 2006 & 2007 & 2008 & 2009 & \\
\hline $\begin{array}{l}\text { Demand Response } \\
\text { Analysis report } \\
\text { provides insights } \\
\text { into potential } \\
\text { participation in } \\
\text { industrial DR, } \\
\text { especially AutoDR } \\
\text { Initiate scoping } \\
\text { studies and sub- } \\
\text { metering to assess } \\
\text { potentials and } \\
\text { barriers } \\
\text { Initiate Roadmap } \\
\text { development }\end{array}$ & $\begin{array}{l}\text { Consolidate \& fill in } \\
\text { gaps in industrial DR } \\
\text { market knowledge } \\
\text { Use results to select } \\
\text { new sub-metering } \\
\text { sites \& target more } \\
\text { scoping studies } \\
\text { Work with } \\
\text { stakeholders group } \\
\text { to build consensus \& } \\
\text { ownership of results } \\
\text { \& strategies } \\
\text { Launch DR Tradeoff } \\
\text { tool }\end{array}$ & $\begin{array}{l}\text { Develop/finalize } \\
\text { industrial DR } \\
\text { opportunities strategy } \\
\text { Conduct gap analysis } \\
\text { of DR controls; } \\
\text { develop R\&D plan } \\
\text { Assess success of } \\
\text { DR Tradeoff tool \& } \\
\text { evaluate need for } \\
\text { more tools } \\
\text { Consolidate \& fill gaps } \\
\text { in industrial EE } \\
\text { market knowledge }\end{array}$ & $\begin{array}{l}\text { Work w/stakeholders } \\
\text { to assess success of } \\
\text { industrial strategy } \\
\text { Implement R\&D plan } \\
\text { for enabling controls } \\
\text { Develop new tool } \\
\text { capabilities, if } \\
\text { needed } \\
\text { Collect \& analyze } \\
\text { DR program } \\
\text { implementation data } \\
\text { Develop strategy to } \\
\text { link industrial DR \& } \\
\text { EE }\end{array}$ & $\begin{array}{l}\text { IOUs can target } \\
\text { industries/systems that } \\
\text { offer best opportunities } \\
\text { for DR, have capacity to } \\
\text { integrate EE \& DR } \\
\text { program activities } \\
\text { Industry may choose } \\
\text { among technically } \\
\text { feasible \& economically } \\
\text { attractive DR offerings } \\
\text { DRRC continues } \\
\text { program analysis \& } \\
\text { suggests refinements \& } \\
\text { technology R\&D, as } \\
\text { needed }\end{array}$ \\
\hline
\end{tabular}




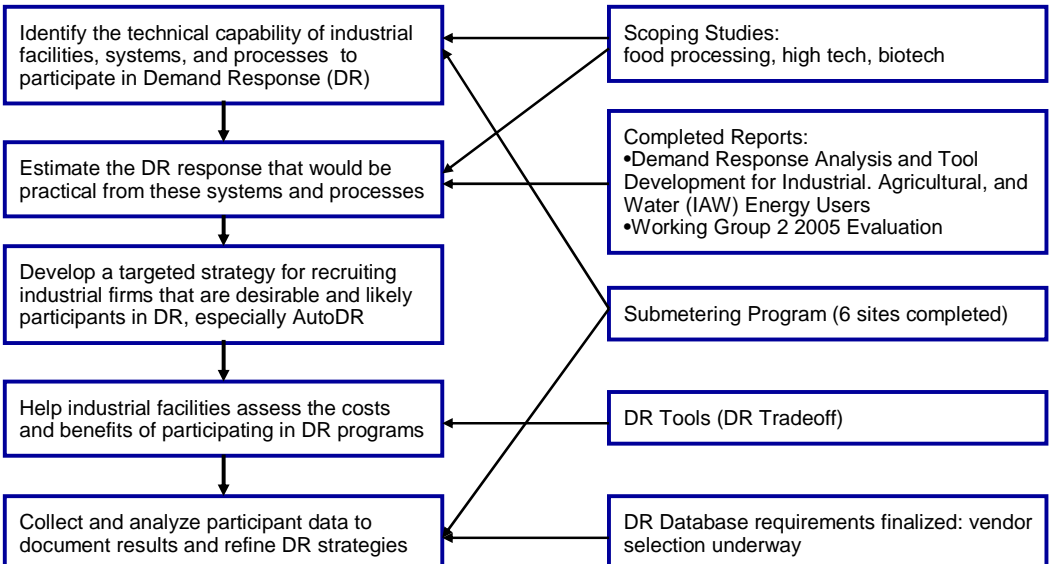

\section{Program Asset Details}

- Scoping studies

Sector-specific studies conducted by industry experts to determine specific DR opportunities in these sectors

- Completed Reports

Summaries and evaluations of existing program activities; key findings from a first-order analysis of sector-based opportunities in CA

- Submetering Program

Submetered data resulting from installations in industrial facilities participating in DR programs

- DR Tools

A basic tool, DR Tradeoff Tool, has been developed that can be used by industrial facilities to evaluate expected savings under different tariff scenarios based on a facility's loads and DR performance

\section{- DR Database}

Designed as a research tool to collect and analyze DR data from C\&l participants. A requirements document has been developed; vendor selection is underway, data is available and ready to load. 
During 2007, the PIER Industrial DR Research Program Activities will be focused on three major themes:

1. Consolidate and fill in the gaps in industrial DR market knowledge

- Analyze the results of 3 scoping studies now underway

- Analyze the results of 6 submetering case studies

- Integrate existing research on industrial system \& process energy use

- Use the results to target 2-3 additional sectors for scoping studies

- Conduct plant validation surveys in 6 sectors (36 surveys total)

- Collect and analyze industrial data from industrial DR participants

2. Test tools and enabling technologies

- Continue submetering program in 6 more sites

- Complete testing of the DR Tradeoff Tool

Proposed Program 2007

3. Work with stakeholders (IOUs, industry, controls vendors) to develop and build ownership for statewide approach to industrial

DR

- Host a series of stakeholder meetings and webcasts

- Seek to develop consensus on a workable program design(s) for AutoDR

- Seek to develop consensus on target industries by region

- Explore synergies between energy efficiency (EE) and DR programs 
Proposed Program 2008

\section{During 2008, the PIER DR Research Program Activities will be focused on 5 major themes:}

1. Integrate data collected and analysis of industrial markets undertaken in 2007 to draft a focused strategy for industrial DR in California

- Analyze results from 2-3 additional scoping studies, 36 plant validation surveys, 10-12 submetering sites, DR Database, and prior analyses

- Cross walk results from these analyses with results of industrial system \& process energy use

- Consult with stakeholders (IOUs, industry, control vendors) on the results

- Develop draft Industrial DR opportunities strategy that considers technical, economic, and managerial factors

2. Work with the CEC and stakeholders to finalize industrial DR opportunities strategy

- Facilitate stakeholder discussions on industrial DR opportunities strategy

- Develop a final report that identifies, by industrial sector and system, the most favorable opportunities for DR, especially AutoDR 
3. Develop an R\&D plan to address enabling control technology gaps for industrial sectors and systems targeted in the DR strategy

- Work closely with industry and control vendors to distinguish technical gaps from economic gaps (does gap result from lack of technology, lack of cost-effective technology, or other factors unrelated to control technologies?)

- Develop an R\&D plan that identifies categories of technologies that have promise for addressing gaps

- Conduct an analysis using a stage-gate type approach to determine how and if to invest R\&D funds for control technology development

4. Decide on the role and relative importance of DR Tools

- Determine the uptake and value of the DR Tradeoff Tool

- Work with stakeholders group to determine if a Valuation Tool should be developed or Tradeoff Tool enhanced

- Develop an overall strategy for DR Tools that supports ongoing DR efforts and the industrial DR opportunities strategy

5. Consolidate and fill in the gaps in industrial energy efficiency market knowledge needed to link with DR

- Integrate existing research on industrial system \& process energy use

- Collect and analyze information on industrial energy efficiency program participation at IOUs, CEC, and DOE

Proposed Program Activities 2008

\begin{tabular}{|c|c|}
\hline Research Need & Program Element \\
\hline $\begin{array}{l}\text { Identify the technical capability of industrial } \\
\text { facilities, systems, and processes to } \\
\text { participate in Demand Response (DR) }\end{array}$ & $\begin{array}{l}\text { Integrate results of scoping studies and validation } \\
\text { surveys into previous program findings to prepare } \\
\text { Industrial DR opportunities strategy }\end{array}$ \\
\hline & Submetering Program (10 existing +4 new sites) \\
\hline $\begin{array}{l}\text { Estimate the DR response that would be } \\
\text { practical from these systems and processes }\end{array}$ & $\begin{array}{l}\text { Identify any enabling control technology gaps and } \\
\text { develop an R\&D plan to address them }\end{array}$ \\
\hline \multirow{3}{*}{$\begin{array}{l}\text { Develop a targeted strategy for recruiting } \\
\text { industrial firms that are desirable and likely } \\
\text { participants in DR, especially AutoDR }\end{array}$} & $\begin{array}{l}\text { Integrate existing industrial EE research \& program } \\
\text { participation; identify links to DR }\end{array}$ \\
\hline & \multirow{2}{*}{$\begin{array}{l}\text { Host quarterly stakeholder meetings with IOUs, } \\
\text { industry, control vendors to obtain program } \\
\text { implementation feedback; refine program. }\end{array}$} \\
\hline & \\
\hline $\begin{array}{l}\text { Help industrial facilities assess the costs } \\
\text { and benefits of participating in DR programs }\end{array}$ & $\begin{array}{l}\text { DR Tradeoff Tool user info from IOUs and industrial } \\
\text { facilities; develop a DR Tool Strategy; if needed, } \\
\text { develop Valuation Tool or enhance Tradeoff Tool }\end{array}$ \\
\hline $\begin{array}{l}\text { Collect and analyze participant data to } \\
\text { document results and refine DR strategies }\end{array}$ & $\begin{array}{l}\text { DR Database continues to grow as DR data is } \\
\text { received from IOU programs on industrial } \\
\text { participants; analysis is conducted to further inform } \\
\text { program activities }\end{array}$ \\
\hline
\end{tabular}


During 2009, the PIER DR Research Program Activities will be focused on 5 major themes:

1. Implement R\&D Plan for enabling control technologies

- Develop targeted solicitations for development or enhancement of control technologies to address gaps

- Use stage-gate process to manage investment of funds and pick the most promising technologies

2. Continue to collect and analyze data from industrial DR experience

- Use data from DR Database, which includes information from IOU implementation programs, submetering cases, and historical information from 2005 evaluation

- Analyze use of DR Tools

Proposed Program 2009

3. Work with stakeholders to determine effectiveness of industrial DR opportunities strategy

- $\quad$ Provide a forum for sharing information -- on program design, response of industry, successes and barriers

- Provide results from analysis of DR database

- Fine-tune research agenda based on feedback from IOUs, industry, control vendors

- Integrate DR lessons learned into EE programs

4. Work with stakeholders to develop a combined industrial EE and DR opportunities strategy

- Build on the experience with the DR strategy

- Facilitate stakeholder discussions

- Develop a final report that identifies, by industrial sector and system, the most favorable opportunities for a combined EE and DR approach

5. Depending on results from 2008 , implement DR Tools strategy

- Supports ongoing DR efforts and the industrial DR opportunities strategy

- Focuses on tool development that addresses specific barriers to industrial DR participation 
Proposed Program Activities 2009

\section{Research Need}

Identify the technical capability of industria facilities, systems, and processes to participate in Demand Response (DR)

\section{Program Element}

Implement R\&D plan for enabling control technologies as needed to implement Auto DR

Continue Submetering Program (14 existing sites)

Estimate the DR response that would be

practical from these systems and processes \begin{tabular}{|l|}
\hline \multicolumn{1}{|c}{ Develop a targeted strategy for recruiting } \\
industrial firms that are desirable and likely
\end{tabular} participants in DR, especially AutoDR

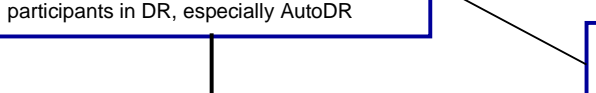

Host periodic webcasts and an annual meeting with IOUs, industry, and control vendors to share

program experience and discuss opportunities fo refining the Industrial DR Opportunities Strategy

Help industrial facilities assess the costs

and benefits of participating in DR programs

Develop combined industrial EE and DR

opportunities strategy in cooperation w/stakeholders

Test DR Valuation Tool, if developed

Collect and analyze participant data to document results and refine DR strategies
DR Database continues to grow as DR data is received from IOU programs on industrial

participants; analysis is conducted to further inform program activities 


\section{Appendix B: Industrial Demand Response Audit Database Structure}

The Demand Response audit database is structured around two main tables: "Audit Info" and "Measure" that are linked together in a one to-many relationship. Each record (or Audit ID) in the Audit Info table is linked to a maximum of six demand response measures that are listed in the Measure table.

The Audit Info table contains the following fields:

- Audit ID

- Utility

- Utility ID

- City

- Date of audit

- Audit Consultant

- Description of the process in the plant

- 6 \& 4-digit NAICS codes

- Utility Sector (used only for PG\&E audits)

- AS Rep (used only for the PG\&E audits)

- Div Code (used only for the PG\&E audits)

- CEE Lead (used only for the PG\&E audits)

- EMS Info (not well populated)

- $\mathrm{kW}$ (maximum $\mathrm{kW}$ )

- Annual kW

- Annual Therms (not well populated)

- EE kW Potential (not well populated)

- EE kWh Potential (not well populated)

- EE Recommendations (not well populated)

- Descriptions of Demand Response recommendations

- Demand Response Potential kW

The Measure table contains the following fields:

- Audit ID

- Measure ID

- General description of the technologies affected by the demand response

- Specific description of how the technology is modified

- Savings in kWh (not well populated)

- Savings in $\mathrm{kW}$

- Strategy (choices are listed below)

o Shift Support

o Shift Production

o Shed Support

o Shed Production

- Strategy Detail (choices are listed below)

o Decrease 

o Pre-cool
o Raise Setpoint
o Recover
o Storage

- Technology (choices are listed below)

o Aerators

o All (the whole facility shuts off)

o Battery chargers

o Compressed air systems

o Conveyors

o Crushers

o Electrical

o Fan systems

o Fume hoods

o Grinders

o Lighting

o Mixers

o Motors

o Multiple

o Process cooling

o Process heating

o Pump system

o Refrigeration

o Space conditioning

o Storage

o Transport system

o Ventilation

o Welding

- $\quad$ Process/Tech Detail (choices are listed below)

o Aerators - water

o Aerators -wastewater

o Fans - agricultural

o Fans - process

o Fans - warehouse

o Process heat - baking

o Process heat - chemical reaction

o Process heat - drying

o Process heat - melting

o Process heat - sterilization

o Pump - product

o Pump - water

o Pump - wastewater

o Refrigeration - chilled water

o Refrigeration - cold storage

o Refrigeration - freezing

- Max duration (not well populated) 


\section{Appendix C: Industrial Demand Response Audit Database Analyses}

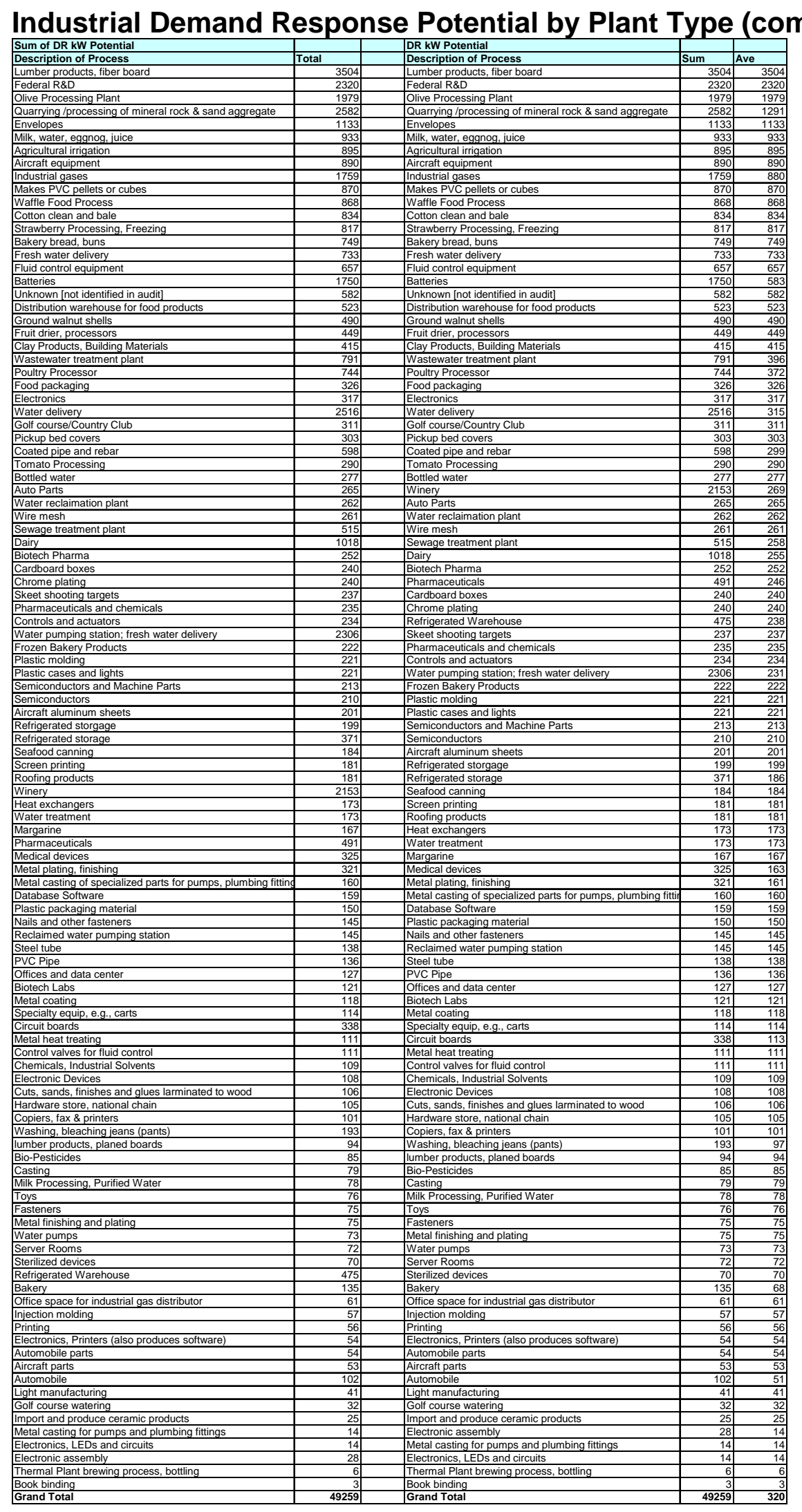




\begin{tabular}{|c|c|c|c|}
\hline \multirow[b]{2}{*}{$\begin{array}{l}\text { 4-Digit } \\
\text { NAICS Code }\end{array}$} & \multirow[b]{2}{*}{ NAICS Description, 2007} & \multicolumn{2}{|c|}{ DR kW Potential } \\
\hline & & Sum & Ave \\
\hline 3211 & Sawmills and Wood Preservation & 3598 & 1799 \\
\hline 2123 & Nonmetallic Mineral Mining and Quarrying & 2582 & 1291 \\
\hline 3222 & Converted Paper Product Manufacturing & 1133 & 1133 \\
\hline 5417 & Scientific Research and Development Services & 2693 & 898 \\
\hline 3114 & Fruit and Vegetable Preserving and Specialty Food Manufacturing & 4403 & 881 \\
\hline 3331 & Agriculture, Construction, and Mining Machinery Manufacturing & 1729 & 865 \\
\hline 3251 & Basic Chemical Manufacturing & 1868 & 623 \\
\hline 3359 & Other Electrical Equipment and Component Manufacturing & 1750 & 583 \\
\hline 3252 & Resin, Synthetic Rubber, and Artificial Synthetic Fibers and Filaments Ma & 1091 & 546 \\
\hline 4529 & Other General Merchandise Stores & 523 & 523 \\
\hline 3115 & Dairy Product Manufacturing & 1011 & 506 \\
\hline 1151 & Support Activities for Crop Production & 490 & 490 \\
\hline 3364 & Aerospace Product and Parts Manufacturing & 943 & 472 \\
\hline 3329 & Other Fabricated Metal Product Manufacturing & 768 & 384 \\
\hline 3116 & Animal Slaughtering and Processing & 744 & 372 \\
\hline 3149 & Other Textile Product Mills & 303 & 303 \\
\hline 3312 & Steel Product Manufacturing from Purchased Steel & 598 & 299 \\
\hline 2213 & Water, Sewage and Other Systems & 7441 & 286 \\
\hline 3118 & Bakeries and Tortilla Manufacturing & 1106 & 277 \\
\hline 1121 & Cattle Ranching and Farming & 1018 & 255 \\
\hline 3121 & Beverage Manufacturing & 2436 & 244 \\
\hline 3221 & Pulp, Paper, and Paperboard Mills & 240 & 240 \\
\hline 3271 & Clay Product and Refractory Manufacturing & 440 & 220 \\
\hline 3339 & Other General Purpose Machinery Manufacturing & 633 & 211 \\
\hline 4931 & Warehousing and Storage & 1045 & 209 \\
\hline 3326 & Spring and Wire Product Manufacturing & 406 & 203 \\
\hline 3313 & Alumina and Aluminum Production and Processing & 201 & 201 \\
\hline 7139 & Other Amusement and Recreation Industries & 580 & 193 \\
\hline 3254 & Pharmaceutical and Medicine Manufacturing & 767 & 192 \\
\hline 4244 & Grocery and Related Product Merchant Wholesalers & 184 & 184 \\
\hline 3241 & Petroleum and Coal Products Manufacturing & 181 & 181 \\
\hline 3324 & Boiler, Tank, and Shipping Container Manufacturing & 173 & 173 \\
\hline 3112 & Grain and Oilseed Milling & 167 & 167 \\
\hline 3345 & Navigational, Measuring, Electromedical, and Control Instruments Manuf & 325 & 163 \\
\hline 3363 & Motor Vehicle Parts Manufacturing & 319 & 160 \\
\hline 5112 & Software Publishers & 159 & 159 \\
\hline 3332 & Industrial Machinery Manufacturing & 757 & 151 \\
\hline 3328 & Coating, Engraving, Heat Treating, and Allied Activities & 865 & 144 \\
\hline 3261 & Plastics Product Manufacturing & 286 & 143 \\
\hline 3311 & Iron and Steel Mills and Ferroalloy Manufacturing & 138 & 138 \\
\hline 3371 & Household and Institutional Furniture and Kitchen Cabinet Manufacturing & 114 & 114 \\
\hline 3212 & Veneer, Plywood, and Engineered Wood Product Manufacturing & 106 & 106 \\
\hline 4441 & Building Material and Supplies Dealers & 105 & 105 \\
\hline 3333 & Commercial and Service Industry Machinery Manufacturing & 101 & 101 \\
\hline 3344 & Semiconductor and Other Electronic Component Manufacturing & 805 & 101 \\
\hline 3133 & Textile and Fabric Finishing and Fabric Coating Mills & 193 & 97 \\
\hline 5311 & Lessors of Real Estate & 188 & 94 \\
\hline 3231 & Printing and Related Support Activities & 184 & 92 \\
\hline 3253 & Pesticide, Fertilizer, and Other Agricultural Chemical Manufacturing & 85 & 85 \\
\hline 3315 & Foundries & 253 & 84 \\
\hline 3399 & Other Miscellaneous Manufacturing & 76 & 76 \\
\hline 3327 & Machine Shops; Turned Product; and Screw, Nut, and Bolt Manufacturind & 75 & 75 \\
\hline 5182 & Data Processing, Hosting, and Related Services & 72 & 72 \\
\hline 3391 & Medical Equipment and Supplies Manufacturing & 70 & 70 \\
\hline 3341 & Computer and Peripheral Equipment Manufacturing & 54 & 54 \\
\hline 3361 & Motor Vehicle Manufacturing & 102 & 51 \\
\hline Grand Total & & 48677 & 318 \\
\hline
\end{tabular}




\section{Appendix D: Questions to Add to Integrated Energy Audit Template for Industrial Facilities}

1) Do you have any process or system that can:

(check all applicable)

_shift to off-peak operation

_shift to a non-critical day

_ temporarily operate differently (e.g. at raised set points, operated at reduced output or using stored energy)

_be interrupted temporarily, from 15 minutes to 8 hours

without having an unacceptable impact on production?

2) In the table below, please check all applicable boxes for functional areas might offer demand response potential:

\begin{tabular}{|c|c|c|c|c|c|c|c|c|c|c|c|c|c|c|c|c|c|c|c|c|}
\hline \multirow[t]{3}{*}{ Functional Area } & \multirow{3}{*}{\begin{tabular}{||l} 
DR \\
Potential \\
(check all \\
applic)
\end{tabular}} & \multirow{2}{*}{\multicolumn{5}{|c|}{\begin{tabular}{|c|} 
Potential Duration (in \\
hours)
\end{tabular}}} & \multicolumn{8}{|c|}{ Potential Frequency } & \multirow{2}{*}{\multicolumn{2}{|c|}{\begin{tabular}{|c|} 
DCS \\
Controls \\
\end{tabular}}} & \multirow{2}{*}{\multicolumn{4}{|c|}{ Required Notice }} \\
\hline & & & & & & & \multicolumn{4}{|c|}{ times per month } & \multicolumn{4}{|c|}{ consecutive days } & & & & & & \\
\hline & & $<2$ & 2 & 4 & 6 & $>6$ & 1 & 2 & 3 & 4 & 2 & 3 & 4 & $4+$ & $\mathrm{Y}$ & $\mathrm{N}$ & $1 \mathrm{hr}$ & $4 \mathrm{hrs}$ & 1 day & $>1$ day \\
\hline shipping and recei & & & & & & & & & & & & & & & & & & & & \\
\hline materials handling & & & & & & & & & & & & & & & & & & & & \\
\hline $\begin{array}{l}\text { support systems- } \\
\text { air, fans, industrial }\end{array}$ & & & & & & & & & & & & & & & & & & & & \\
\hline production process & & & & & & & & & & & & & & & & & & & & \\
\hline packaging & & & & & & & & & & & & & & & & & & & & \\
\hline warehouse & & & & & & & & & & & & & & & & & & & & \\
\hline space conditioning & & & & & & & & & & & & & & & & & & & & \\
\hline lighting & & & & & & & & & & & & & & & & & & & & \\
\hline onsite generation & & & & & & & & & & & & & & & & & & & & \\
\hline other: & & & & & & & & & & & & & & & & & & & & \\
\hline
\end{tabular}

3) Does your facility have a Distributed Control System (DCS) or other automation system? _ yes _ no

If no, what is used to control your industrial processes?

_Manual

_Semi-automatic, such as programmable timer, please describe-

_Other, please describe-

4) Assuming advance notification (via phone, text message, pager or e-mail) and "opt-out” option via a Web page, how suitable is your site for automated demand response for some portion of the electric load (i.e., pre-determined loads would shed automatically without staff intervention): (check one).

_ Suitable for automated demand response.

_ May be suitable for automated demand response.

_ Not suitable for automated demand response 
Appendix E: Site Questionnaire

\section{Site Questionnaire}

Thank you for completing this survey. When completed, please e-mail to cpjoe@gepllc.com or fax to 925.284.3147.

\begin{tabular}{|l|l|}
\hline Interviewer & \\
\hline Date Interviewed & \\
\hline
\end{tabular}

\section{Contact Information}

\begin{tabular}{|l|l|}
\hline Name & \\
\hline Company & \\
\hline $\begin{array}{l}\text { Contact's } \\
\text { address }\end{array}$ & \\
\hline Phone & \\
\hline Fax & \\
\hline E-mail & \\
\hline Year established & \\
\hline
\end{tabular}

Site Information - industrial sector (check applicable)

\begin{tabular}{|c|c|c|c|c|}
\hline $\begin{array}{l}\text { NAICS } \\
\text { Code }\end{array}$ & Industrial Sector & $\begin{array}{l}\text { NAICS } \\
\text { Code }\end{array}$ & Industrial Sector & \\
\hline 2213 & Water and wastewater treatment & 3323 & \multicolumn{2}{|c|}{ Architectural and Structural Metals } \\
\hline 3114 & Fruit and Vegetable Processing & 3328 & \multicolumn{2}{|c|}{ Coating, Engraving, Heat Treating } \\
\hline 3118 & Bakeries and Tortillas & 3329 & \multicolumn{2}{|c|}{ Other Fabricated Metals } \\
\hline 3121 & Beverages & 3332 & Industrial Machinery & \\
\hline 3132 & \multirow[b]{2}{*}{ Fabric Mills \& Textiles } & 3341 & \multicolumn{2}{|c|}{ Computers and Peripherals } \\
\hline 33,41 & & 3342 & \multicolumn{2}{|c|}{ Communications Equipment } \\
\hline 3222 & Converted Paper Products & 3344 & \multicolumn{2}{|c|}{ Semiconductor/Electronics } \\
\hline 3231 & \begin{tabular}{|l|l|} 
Printing & \\
\end{tabular} & 3363 & Motor Vehicle Parts & \\
\hline 3241 & Petroleum/Coal & 3364 & \multicolumn{2}{|l|}{ Aerospace } \\
\hline 3251 & Basic Chemicals & 3371- & \multirow{2}{*}{\multicolumn{2}{|c|}{$\begin{array}{l}\text { Household \& Office } \\
\text { Furniture/Fixtures }\end{array}$}} \\
\hline 3254 & Pharmaceuticals & 3372 & & \\
\hline 3261 & \begin{tabular}{|l|l|} 
Plastics & \\
\end{tabular} & 4931 & \multicolumn{2}{|c|}{ Warehousing and Storage } \\
\hline 3262 & Rubber Products & 5182 & & \\
\hline 3273 & Cement and Concrete & 5622 & \multicolumn{2}{|c|}{ Waste Treatment and Disposal } \\
\hline \multicolumn{5}{|l|}{ Dother_ } \\
\hline Site Addre & & & & \\
\hline
\end{tabular}




\begin{tabular}{|c|c|}
\hline Number of Employees & \\
\hline $\begin{array}{l}\text { Approx Building } \\
\text { Square Footage }\end{array}$ & \\
\hline $\begin{array}{l}\text { Product type (s) } \\
\text { manufactured at this } \\
\text { site }\end{array}$ & $\begin{array}{l}(1) \\
(2) \\
(3)\end{array}$ \\
\hline $\begin{array}{l}\text { Production per year by } \\
\text { Product type (Units, } \\
\text { lbs, volume) }\end{array}$ & $\begin{array}{l}\text { Product (1): } \\
\text { Product (2): } \\
\text { Product (3): }\end{array}$ \\
\hline Process Type & $\begin{array}{ll}\square \text { Batch } & \square \text { Both or Varies } \\
\square \text { Continuous } & \end{array}$ \\
\hline Hours of Operation & $\begin{array}{l}\square 1 \text { shift/5 days } \quad \square 1 \text { shift/7 days } \\
\square 2 \text { shifts/5 days } \square 2 \text { shifts/7 days } \\
\square \quad 24 / 7\end{array}$ \\
\hline Scheduled Shutdown & $\begin{array}{l}\square \text { Yes } \square \text { No } \\
\text { If yes, } \square \text { during the period from May-Sept } \\
\square \text { other }\end{array}$ \\
\hline Facility Operations & $\begin{array}{l}\text { Do you have any of the following onsite: } \\
\square \text { wastewater treatment } \\
\square \text { data center } \\
\square \text { storage for cooling water, industrial gases, or de-ionized water }\end{array}$ \\
\hline Outsourced Operations & $\begin{array}{l}\square \text { Bldg management } \\
\square \text { Production process or service, describe }\end{array}$ \\
\hline & $\begin{array}{l}\square \quad \text { Other outsourcing } \\
\square \quad \text { No outsourcing }\end{array}$ \\
\hline
\end{tabular}

\section{Energy}

\begin{tabular}{|l|l|l|}
\hline Utility Company & \multicolumn{2}{|l|}{} \\
\hline Peak load [kW] & \multicolumn{2}{|l|}{} \\
\hline Connected load [kW] & & \\
\hline $\begin{array}{l}\text { Approximate breakdown of } \\
\% \text { load during summer }\end{array}$ & Production Processes & \\
\hline
\end{tabular}




\section{Process Equipment}

In addition to any previous demand response participation, can any Process Equipment be Shutdown or Throttled back for at least 2 consecutive hours between the hours of 12:00PM and 8:00PM, during critical demand days from May 1 thru Oct. 31? $\square$ Yes $\square$ No

3. The Auto-DR Hardware is designed communicate a DR event directly to control systems and/or can be used to turn off Can Auto-DR hardware be allowed to shutdown any process equipment at the start of a DR event? loads.

\begin{tabular}{|l|l|l|}
\hline Yes & $\square$ & If yes, go to 4 \\
\hline No & $\square$ & If no, go to 6 \\
\hline
\end{tabular}

4. List process equipment and estimated $\mathrm{kW}$ that can be shutdown or throttled for at least 2 consecutive hours when the Utility calls for a DR event.

\begin{tabular}{|l|l|}
\hline Name and Description of Equipment & kW \\
\hline & \\
\hline & \\
\hline & \\
\hline
\end{tabular}

5. Could all of the process equipment listed above tolerate a demand event on two consecutive days? (Shutdown or throttled for at least two hours on each event day)?

$\square$ Yes $\square$ No--list equipment that could not tolerate two consecutive event days: \begin{tabular}{lr|l} 
6. Some & process & Are there any process machines that could be shutdown if the \\
machines & can be & operator is notified in advance of the DR event?
\end{tabular}

shutdown as long as the operator has ample time to either clear all material

\begin{tabular}{|l|l|l|}
\hline Yes & $\square$ & If yes, go to 7 \\
\hline No & $\square$ & If no, go to 8 \\
\hline
\end{tabular}
or complete a cycle.

7.List process equipment and estimated $\mathrm{kW}$ that can be shut down for at least two consecutive hours with advance notice

\begin{tabular}{|l|l|l|}
\hline Name and Description of Equipment & Kw & $\begin{array}{c}\text { Advance } \\
\text { Notice Req'd } \\
\text { (in hrs) }\end{array}$ \\
\hline & & \\
\hline & & \\
\hline & & \\
\hline
\end{tabular}




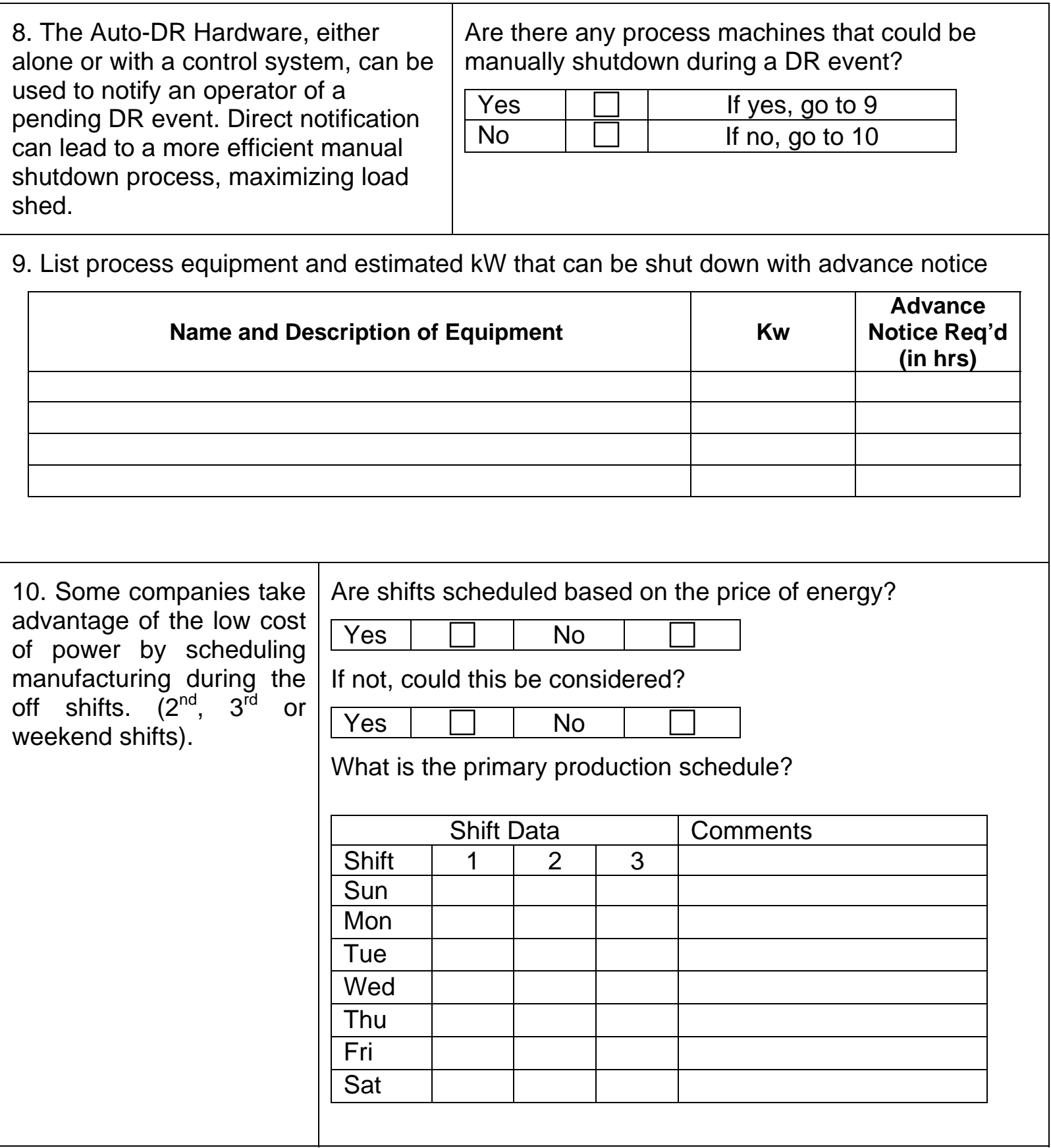




\section{Building Equipment}

Can any Building Equipment be Shutdown or Throttled back for at least 2 consecutive hours between the hours of 12:00PM and 8:00PM, during 12 DR days from May 1 thru Oct. $31 ?$

10. Building systems like HVAC and lighting loads have been proven to be a great source of DR load shed opportunity
Are there any buildings that utilize an Energy Management Control System (EMCS) to control temperature?

Yes $\square$ No $\square$ yes, are Lights controlled by the EMCS? Yes $\square$ No $\square$

EMCS systems have been paramount in optimizing the efficiency of building systems.

Are there any areas conditioned by an HVAC system that could tolerate a temperature change for a short period of time?

\begin{tabular}{|l|l|l|l|}
\hline Yes & $\square$ & No & $\square$ \\
\hline
\end{tabular}
HVAC systems.

12. Since DR event occur during high demand time, typically during daylight hours, depending on circuit configurations, lighting fixtures may be another source of load shed opportunity.

Are lighting circuits configured such that the total lumens in an area could be reduced by $25 \%, 50 \%$, or $75 \%$ by isolating lighting circuits?

\begin{tabular}{|l|l|l|l|}
\hline Yes & $\square$ & No & $\square$ \\
\hline
\end{tabular}

Can certain lighting circuits be turned off during the day without affecting throughput?

\begin{tabular}{|l|l|l|l|}
\hline Yes & $\square$ & No & $\square$ \\
\hline
\end{tabular}

\section{Backup Power}

13. A common solution to maintain throughput during a sustained power interruptions is to power the equipment from a motor-generator and/or mobile air compressor.
Does your site have a backup power source or mobile air compressor?

\begin{tabular}{|l|l|l|l|}
\hline Yes & $\square$ & No & $\square$ \\
\hline
\end{tabular}

If yes, could the backup system be used during a DR event?

\begin{tabular}{|l|l|l|l|}
\hline Yes & $\square$ & No & $\square$ \\
\hline
\end{tabular}

If yes, what is the approximate kW?

Does the motor-generator and/or compressed air systems come on-line automatically if a power interruption is detected?

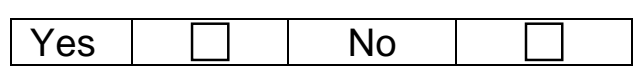
DR hardware to transfer power directly to backup systems. 
Other Equipment

15. Are there any other equipment that could be turned off or throttled back for at least 2 consecutive hours between the times of 12:00PM and 8:00PM, from May 1 thru Oct. 31? Please list potential loads

\begin{tabular}{|l|c|}
\hline Name and Description of Equipment & kW \\
\hline & \\
\hline & \\
\hline & \\
\hline
\end{tabular}

If you have any questions about this survey, please contact Joe Prijyanonda at Global Energy Partners, LLC. He can be reached at 925.284.3780 or at cpjoe@gepllc.com.

Global Energy Partners is located at the following address:

3569 Mt. Diablo Boulevard, Suite 200

Lafayette, California 94549

www.gep/lc.com 


\section{Appendix F: Fact Sheets}

Demand Response Research Center

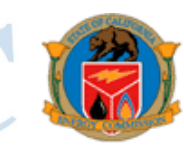

\section{Automated Demand Response (Auto-DR) For Industry Overview}

\section{What is being proposed?}

Demand Response (DR) is a set of actions taken to reduce electric loads when contingencies, such as emergencies or congestion, occur that threaten supply-demand balance, and/or market conditions occur that raise electric supply costs. Demand response programs and tariffs are designed to improve the reliability of the electric grid and to lower the use of electricity during peak times to reduce the total system costs. Automated Demand Response (Auto-DR) is a set of standard, continuous, open communication signals provided over the Internet to allow facilities to automate their demand response with no "human in the loop."

\section{Who initiated this idea?}

The Demand Response Research Center (DRRC) < http://drrc.lbl.gov>, which is sponsored by the California Energy Commission's (CEC) Public Interest Energy Research (PIER) Program, has been developing standard methods to automate demand response.

The DRRC has tested Auto-DR systems in 40 commercial buildings over the last four years. Most of the building strategies have focused on lighting and cooling system strategies. Previous work has focused on building Energy Management Systems. The DRRC is actively evaluating strategies, techniques, and the application of Auto-DR for industrial facilities.

\section{Why Auto-DR for industry?}

In California industry represents $20 \%$ of base electricity peak demand, or approximately $8600 \mathrm{MW}$. Initial estimates indicate that as much as $30-40 \%$ of industrial loads may be automatic demand response (Auto-DR) candidates ${ }^{1}$.

Automating demand response will make DR more visible, repeatable, reliable, and lower cost:

- More visible because the two-way communication systems allow Internet tracking of the receipt of DR signals from end-use customers.

- More repeatable and reliable because the DR signals trigger fully automated controls strategies that are "hardened" and programmed into software and hardware.

- More affordable because automation can help reduce labor costs associated with manual DR strategies initiated by facility staff.

${ }^{1}$ PIER Demand Response R\&D Strategy, Commissioner Geesman Briefing August 24, 2006 
Which utility service territories offer Auto-DR programs?

In California, Pacific Gas and Electric (PG\&E), Southern California Edison (SCE) and San Diego Gas and Electric (SDG\&E), currently/plan to offer Auto-DR to facilities through their own programs. "Direct-Access ${ }^{16 ”}$ industrial facilities customers are also eligible to participate in the DR programs offered within the service territories of these utilities.

\section{What's the value proposition for industry?}

- Financial

o Lower electricity bills. Reducing energy consumption during high-price periods cuts energy costs.

o Several demand response programs offer financial and other benefits to businesses that can reduce electric load during periods of extreme usage.

- Reliability

o Reducing peak energy use helps eliminate exposure to rotating outages.

- Environmental

o Cutting electricity is the most environmentally sound way of securing power reducing use minimizes the need for generation and therefore, the amount of emissions released into the air from the production of electricity. ${ }^{17}$,

- Social

o Your neighborhood will benefit too - lights will stay on, businesses will keep running and people that rely on electrical equipment, often schools and the elderly, will not suffer from power disruptions.

\section{How will Auto-DR work and what will it include?}

Auto-DR requires standardized signals between different utilities and industrial facilities based on standardized communication technologies that integrate with third-party proprietary controls and communications software.

The essential elements of an Auto-DR system are shown in the figure below and include:

- Demand Response Automation Server (DRAS) for Auto-DR (OpenADR) is based on the interoperable, open-standard architecture using Web Service ${ }^{18}$ software system.

- Client \& Logic with Integrated Relay (CLIR) box, XML software gateway, etc., that fit into individual deployment requirements for a facility and provides flexibility for enrollment.

- Energy Management Control Systems, Energy Information Systems (EMCS/EIS) or other forms of building automation are used for DR strategies within the facility.

\footnotetext{
${ }^{16}$ Direct Access Customers are those who engage in accessing their energy needs directly with electric service providers such as Calpine, Strategic Energy, etc.

${ }^{17}$ Flex Your Power, http://www.fypower.org/now/demand_resp_faq.html\#what_adv. Accessed April 3, 2007

${ }^{18}$ Web services (WS) is a set of modular applications that are self-describing and self-contained that can be easily integrated with other Web services to create objects and processes. WS are built using open Internet standards, thus enabling systems to be constructed and integrated with applications on any platform and programming language.
} 


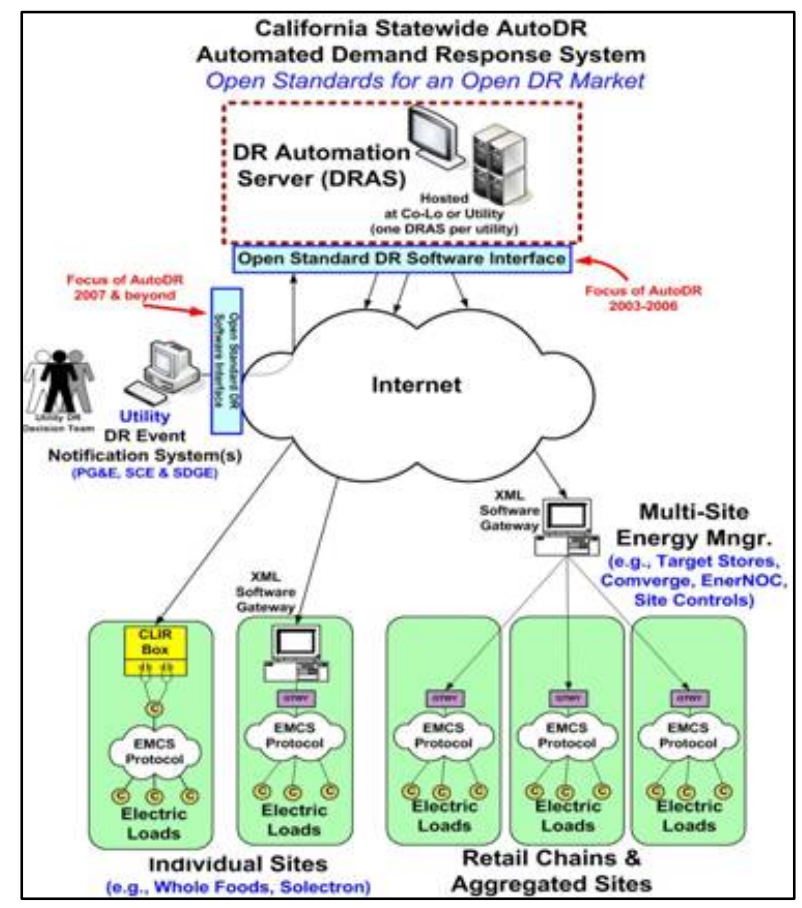

What types of programs are available?

Presently the following types programs are offered:

- Automated Critical Peak Pricing (Auto-CPP), offered by PG\&E and SCE, is a form of priceresponsive demand response that automates the demand response for critical days as part of a critical peak pricing tariff.

o PG\&E: http://www.pge.com/biz/demand_response/critical_peak_pricing

o SCE: http://www.sce.com/RebatesandSavings/LargeBusiness/DemandResponse

- The Automated Demand Bidding Program (Auto-DBP), offered by PG\&E, is also a form of price-response that allows participants to provide a bid for a certain load shed level (kW) during a two to 8 hour period.

o PG\&E: http://www.pge.com/biz/demand_response/demand_bidding_program

- The Automated Capacity Bidding Program (Auto-CBP), is currently under consideration by SDG\&E, is voluntary and a form of reliability demand response and is based on certain guaranteed monthly payments on an agreed level of bid load reduction at fixed price when requested. It comes w/ more incentives for load reduction during critical peak days in summer.

o SDG\&E: http://www.sdge.com/drp/glance.shtml

Who else will be involved?

- Private companies subcontracted by utilities to commercialize Auto-DR systems

- Industrial energy management experts

- Governmental and Non-governmental organizations

What is the process for participation?

The DR programs are different among utilities. For PG\&E’s Auto-CPP and Auto-DBP programs, participants have to go through an application process subcontracted by PG\&E to Global Energy Partners, LLC (GEP) http://www.gepllc.com. 
- DRRC - http://drrc.lbl.gov

- Flex Your Power information program provides a summary of voluntary and utility sponsored DR concepts and programs in California:

o http://www.fypower.org/now/demand_resp.html

o http://www.fypower.org/now/demand_resp_faq.html

- $\quad$ PG\&E Auto-DR program details - http://www.auto-dr.com (under construction)

- PG\&E DR - http://www.pge.com/demandresponse/;

- SCE DR - http://www.sce.com/RebatesandSavings/LargeBusiness/DemandResponse/

- SDG\&E DR - http://www.sdge.com/drp/glance.shtml

Lawrence Berkeley National Laboratory Contact(s)

Aimee T. McKane ATMcKane@lbl.gov 518.782.7002

Anthony Radspieler Jr. ARadspieler@lbl.gov 510.486.2799

http://drrc.lbl.gov 


\section{Demand Response (DR) Strategies for Data Centers}

\section{Introduction and Background}

DRRC classifies data centers under industrial category based on their machine-centric and industry-like characteristics. These DR strategies for data centers are considered specific due to their underlying existing strategies, high-level of technology implementation, and the awareness of technical knowledge, which make their DR participation unique, especially in implementing these strategies for automated DR (AutoDR).

\section{Objectives and Purpose}

To identify the potential research and application strategies for data centers participation in DR and AutoDR. This potential will be largely dependent on the controls environment, especially the automation capabilities of energy management control systems or energy information systems (EMCS/EIS), for DR and AutoDR. These controls and/or automations are necessary to get event notification signals from utilities.

Outlined below are some potential strategies and participation benefits for the data centers with emphasis on AutoDR programs such as Critical Peak Pricing (CPP) and Demand Bid Program (DBP). Participation benefits are available within the customers of Pacific Gas \& Electric (PG\&E), Southern California Edison (SCE), and San Diego Gas \& Electric (SDG\&E) - or "Direct-Access" customers within the service territories of these utilities. The DR participation corresponds to responding to events during peak summer loads (10-12 utility issued events every year).

\section{Benefits from Participation}

- Financial -

- Lower electricity bills by reducing the energy consumption in form of processing loads during high-price periods on peak event days. Savings can be higher than other industries due reduction in cooling and other environmental controls.

- DR programs offer financial and other incentives to data center businesses that can reduce electric load/consumption during periods of peak demand.

- Large-scale economic impact resulting from black/ brown-outs, which can be prevented.

- Provide a viable means to reduce operating expenses.

- Reliability and Security -

- Maintain the reliability of grids and electricity supply, which otherwise can result in loss of data and revenue, and delays.

- Reducing peak energy consumption eliminates exposure to rotating outages, reduces energy risks, and averts energy crisis.

- Environmental -

- Reducing energy consumption and migration of processing load to other zones or curtailment has positive impacts on the environment and energy conservation.

- Reducing peak day consumption is "most environmentally sound way of securing power reducing use minimizes the need for generation and therefore, the amount of emissions released into the air from the production of electricity. ${ }^{2}$ "

- Meets the sustainability requirement and does not contribute to "global-warming" and/or "Climate Change."

- Social and Societal -

- Reducing peak energy demand benefits society and neighborhood from energy emergencies by making sure lights stay on, businesses keep functioning, and people relying on electrical equipment, often schools and the elderly, will not suffer from power disruptions.

- DR can be incorporated into corporate social responsibility (CSR) policies and values.

\footnotetext{
'Customers who engage in accessing their energy directly from electric service providers such as Calpine, Strategic Energy, etc

${ }^{2}$ FLEX YOUR POWER: hito://www fypower.org/nowidemand resp fac.htm Hwhat adv, Accessed April 6, 2007 


\section{Potential DR and Auto-DR Strategies and Tasks}

The reduction of processing load on computer systems and associated components also lowers cooling or similar load, resulting in two-fold savings quite unique to data centers. The following are some feasible potential strategies and virtualization scenarios specific to data centers. We have grouped these strategies by those within the control by the IT department/infrastructure (IT) and/or the facility-level (FL):

\section{Potential Data Center Specific Strategies}

- Tasks prioritization [IT] -

Existing or new policies, software algorithms can shift low priority tasks on event days, to a noncritical peak time. For example, run back-ups before $12 \mathrm{p} . \mathrm{m}$ or after $6 \mathrm{p} . \mathrm{m}$. Other tasks may include - software and related updates, data replication, system upgrades, etc.

- Demand shift [IT]-

- Most data centers have co-locations in different time or climate zone, sometimes in different states and/or geographic location as backup during crisis. Faster shifting of loads temporarily is possible without much effort using existing or custom technologies. Possible categories are:

1. Server Consolidation or Utilization: Capacity analysis and creation of consolidated server-pool to run fewer server(s). Enabling technology is presently available.

2. Server Virtualization: Process-load management using virtualization to eliminate redundant server(s). Enabling technology is presently available.

3. Shifting of load to co-location. Enabling technology to be ready in summer 2007.

- Environmental Conditions [FL]-

- Data centers with cooling set points at or near the minimum requirements for IT equipment could temporarily reduce demand by allowing the temperature to rise temporarily by a few degrees without any adverse effects.

- Some data centers have back up reserves such as ice storage or chilled-water storage for cooling. These conditions make effective use of these reserves during peak event days.

- Significant reduction of loads is possible through automation and existing technologies through reduced IT equipment load, which when synergized with accompanying loads will lower cooling, lighting, or similar losses. E.g. Zones where demand-shift happens.

- Technology Integration [IT]-

- Data center's high-level technology advancement and expert knowledge benefits integration. For example, Data center EMCS interaction to utility notification and open standard, Demand Response Automation Server (DRAS).

- Aided Research [IT/FL]-

- Use of technology to analyze and simulate DR event for potential benefits and intended action, real-time load management, and end-use monitoring are some research in form of down-stream benefits.

\section{LBNL Contact(s)}

Girish Ghatikar <GGhatikar@1bl.gov> 510.486.6768

Anthony Radspieler Jr. <ARadspieler@1bl.gov> 510.486.2799

Aimee T. McKane<ATMcKane@1bl.gov> 510.782.7002

\section{http://drre.lbl.gov}




\section{Appendix G: Implementation Examples}

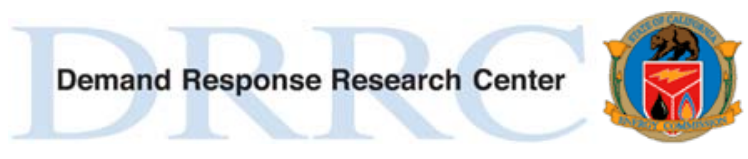

\section{Example of Industrial Auto-DR Application}

\section{Industrial Gas Facilities}

This industrial gas facility produces compressed_industrial gases for bulk distribution. These gases are delivered either via large tanker trucks via direct pipeline. There are about 5 direct pipeline customers, some as far away as 20 miles. The pipeline compressors serving the dedicated pipeline customers are not interruptible. Electricity is their primary cost of production.

At the time of their recruitment into PG\&E's Auto-DR program, the facility was already shifting their production to take advantage of PG\&E time of use and interruptible rates as well as in response to weather impacts on the efficiency of production. As a result, they were accustomed to shifting processes manually. They participated in non-firm manual DBP last year. As illustrated in the table below, they were able to manually shed from between 4.7 and $16.9 \mathrm{MW}$ from baseline. Their main motivation for participation is cost reduction. Under the non-firm scenario, they were required to fix the amount of load to be shed well in advance of the season. Auto-DR participation in DBP provides this company with a greater range of options - providing a greater level of flexibility of response, while preserving the minimum shed commitment. AutoDBP, unlike Auto-CPP is non-penalizing for non-participation and allows variable bids.

The large plant can shed about 9 MW from a peak load of approximately 20 MW within an hour from two compressors. There is another smaller plant that can be shut off, shedding about 1 MW. The facilities plan to make up the shed incrementally by optimizing production during offpeak times. The large plant has a very large storage capacity that can be used for this purpose

During the recruitment process, the facility staff expressed some concern about the impact of an Auto DR signal and automation on their production line. In particular, they had security concerns and AutoDR signaling infrastructure and asked about the CLIR physical location, signals, security implementation, etc. Installation and tests were conducted to determine the feasibility of AutoDR. Compatibility between the facility's existing centralized controls (Allen Bradley) and the Auto-DR signal from DRAS was resolved via software programming completed by company engineers brought in from corporate headquarters and LBNL team.

This type of shift can be replicated in other industrial gas facilities. 